\title{
LA RIVALIDAD COMO ENEMIGO. EL RENDIMIENTO DEL EJÉRCITO DE FLANDES EN EL SITIO DE OSTENDE, 1601-1604
}

\author{
WERNER THOMAS \\ Universidad de Lovaina (KU Leuven)
}

RESUMEN. Durante más de tres años el Ejército de Flandes intentó tomar Ostende, último reducto de la República holandesa en los Países Bajos meridionales. La ubicación de la ciudad, su continuo abastecimiento por el mar, las condiciones atmosféricas, las características del terreno, las diversiones organizadas por Mauricio de Nassau, todos estos elementos dificultaron la toma de la ciudad. Pero no explican todo. La rivalidad entre los cabos y naciones del Ejército, apenas controlada por el capitán general, también desempeñaron un papel principal. Este artículo analiza su rol en el bajo rendimiento de las tropas ante Ostende.

Palabras clave: Ostende, ejército de Flandes, Ambrogio Spínola, sitio, Alberto de Austria

ABSTRACT. During more than three years, the Army of Flanders sieged Ostend, the last stronghold of the Dutch Republic in the Spanish Netherlands. The location of the city, its continuous supply by sea, the weather conditions, the nature of the terrain, and the diversions of Maurice of Nassau's army all hampered the reduction of the city. But they do not fully explain the delay. Rivalry between commanding officers and the different nations of the Army, insufficiently stopped by the captain general, also played an important role. This article analyzes how internal rivalry influenced the efficiency of the Army at Ostend.

Keywords: Ostend, Army of Flanders, Ambrogio Spinola, siege, Albert of Austria 
Al ser la llamada Guerra de los Ochenta Años un conflicto en el que los asedios de ciudades constituían una parte significativa de las actividades militares tanto del ejército de Flandes como de las tropas rebeldes, el sitio que más llamó la atención de los contemporáneos fue sin duda el de Ostende, último enclave protestante en el territorio de los Países Bajos meridionales. Se inició el 5 de julio de 1601 con un cañoneo de la artillería archiducal que, según los cronistas, se escuchó hasta Londres y pronto se convirtió en la mayor confrontación militar europea de inicios del siglo XVII (Henrard, 1890; Vlietinck, 1897, pp. 279-308; De Vos, 1995; Thomas, 2004b; Lombaerde, 2004a). Al describir el ataque general que los sitiadores efectuaron el 7 de enero de 1602 a las posiciones rebeldes, y en el que, en menos de veinticuatro horas, murieron entre 800 y 2.000 soldados del archiduque Alberto —más los centenares de heridos ${ }^{1}$ - el maestre de campo italiano Alonso Dávalos comentó en una carta a Vicenzo I Gonzaga que «homai [ormai] ci si presenta un altro assedio di Troia, ma senza gl'Achilli et quelli altri famosi», siendo uno de los primeros en predecir la larga duración de la empresa ${ }^{2}$. Cuanto más duraba el sitio, más frecuente se hacía la comparación con la Guerra de Troya, y los mismos asediados llamaron la «Nova Troia»al espacio de la ciudad donde se retiraron pocos días antes de su caída. Finalmente, esta Nueva Troya se rindió el 22 de septiembre de 1604, después de un sitio de 1.174 días.

Muchas son las razones por las que la toma de la ciudad se prolongó tanto. En 1600, Ostende era una de las ciudades más fortificadas de Europa, luciendo una muralla con ocho bastiones alrededor de la ciudad nueva hacia tierra adentro y otros ocho protegiendo la ciudad vieja y el puerto desde el mar, todo ello completado por un sistema de media lunas, revellines, contraescarpa y esclusas que, en combinación con el río Geule en su lado septentrional, permitían controlar el nivel del agua en el foso tanto de la ciudad como de la contraescarpa, y, en caso de necesidad, convertirla en una isla (Lombaerde, 2004b). Su ubicación en la costa del condado de Flandes permitía que la flota rebelde pudiese abastecerla con relativa facilidad desde los puertos zelandeses. Tomar la ciudad por asalto tampoco era factible, ya que sus cañones dominaban el terreno circundante, que carecía de elementos protectores, a excepción de una franja estrecha de dunas por el lado del mar. Al mismo tiempo, las mareas dificultaban la construcción de fortificaciones defensivas - trincheras, parapetos - y ofensivas — plataformas, acercamientos, minas - en una zona pantanosa,

1 Antonio CARnero, Historia de las gverras civiles que ha avido en los estados de Flandes desde el año 1559 hasta el de 1609, Bruselas, Jan van Meerbeeck, 1625, p. 486; Histoire remarqvable et veritable de ce qvi s'est passé par chacun iour au siege de la ville d'Ostende, París, Ieremie Perier, 1604, f. 66v; Christophle de Bonours, Le memorable siege d'Ostende, Bruselas, Jan van Meerbeeck, 1628, p. 197*. En el cuarto libro de Bonours, la paginación salta de 199 a 100 en vez de a 200, reiniciando la numeración de las páginas. El asterisco indica que se trata de la segunda serie de páginas con esta numeración.

2 Archivio di Stato Mantua, Archivio Gonzaga, n 575: carta de Dávalos a Gonzaga, Ostende 12 de enero de 1602. Doy las gracias a Maurizio Arfaioli por compartir esta referencia. 
complicando cualquier intento de acercamiento a las defensas de la ciudad. El movimiento del agua también determinaba el ritmo de los asaltos, pues con la marea alta era imposible llegar a la muralla. Finalmente, las maniobras de diversión organizadas por Mauricio de Nassau en el centro y el este del país con el propósito de obligar al archiduque a levantar el sitio, aunque no lograron del todo su objetivo, sí ocasionaron que de forma regular se retirasen tropas del campo para destacarlas en los cuerpos de ejército destinados a socorrer 's-Hertogenbosch (1601 y 1603), Grave (1602) y Sluis (1604), dejando los sitiadores con tropas insuficientes para emprender operaciones ofensivas (Thomas, 2004a).

Sin embargo, el sitio también se prolongó como consecuencia del mal funcionamiento del propio ejército. Precisamente porque duró tanto, los elementos que comprometían su funcionalidad se manifestaron con mayor intensidad. Esto convierte a Ostende en un excelente estudio de caso para analizar el rendimiento de las tropas. Con 'rendimiento' no me refiero a las decisiones tácticas que resultaron infructuosas, a las operaciones que fracasaron a causa de contratiempos naturales o mayor capacidad militar del enemigo, a las derrotas causadas por la falta de dinero y recursos, o al papel de los motines que hacia 1600 eran endémicos (Parker, 1972, pp. 185-206). Me refiero a la manera en la que esa máquina de guerra se bloqueaba por las fricciones entre los oficiales mayores y por la rivalidad entre las naciones, algo ya señalado por González de León (2009). Ambos elementos hipotecaron el rendimiento del ejército y contribuyeron, junto con los otros factores, a la prolongación del sitio.

El tema de la rivalidad entre las naciones que componían el ejército de Flandes no se debe confundir con el de las facciones en la corte de Bruselas (o incluso Madrid). Si bien la lucha de facciones era un campo abonado, sobre todo, para el antagonismo de los protagonistas, la rivalidad en el ejército también se manifestó a nivel de las tropas. No obstante, el mundo de la corte y el del ejército estaban estrechamente vinculados. Tanto los capitanes generales de la caballería y la artillería como el capitán de la guardia de corps del archiduque y varios maestres de campo y coroneles - españoles, borgoñones y flamencos - ocupaban puestos cortesanos, mientras que otros maestres de campo y capitanes se integraron en la corte bajo la condición de «entretenidos cerca de la persona» del capitán general (Thomas, 2014, pp. 206-212). Pero mientras que la lucha entre las facciones cortesanas en Bruselas hasta cierto punto ya se ha estudiado (Lefèvre, 1923 y 1924; Carter, 1964; Thomas, 2011; Raeymaekers, 2013; Thomas, 2014³), el efecto de la rivalidad sobre el fun-

3 Contrariamente a lo que Duerloo y Raeymaekers parecen pensar, ninguno de estos autores, tampoco Lefèvre, considera la facción española en la corte de Bruselas como una facción compuesta exclusivamente por españoles. Todos reconocen su composición diversa. El término «facción española» más bien se refiere al conjunto de consejeros, nobles y militares españoles y locales que interpretaban la política en los Países Bajos desde los intereses de la Monarquía Hispánica, mientras que otro grupo importante - también compuesto por españoles y locales- 
cionamiento concreto del ejército en el campo de batalla, aunque reconocido por todos los historiadores que se ocupan del ejército de Flandes, sólo se ha analizado en contadas ocasiones (Esteban Estríngana, 2012a). Le memorable siege d'Ostende de Christophle de Bonours ofrece una visión única para estudiar esta rivalidad. Esta crónica es uno de los pocos relatos completos del asedio desde el punto de vista del sitiador porque, en efecto, Bonours estuvo en Ostende durante toda la duración del sitio como capitán en el regimiento valón del coronel Nicolás Catrice (Helbig 1868)4. Más importante aún, es el único autor que presta atención no sólo a la ejecución de las órdenes y resoluciones del alto mando, sino también al proceso de toma de decisiones precedente y a la dinámica entre los cabos, y esto con un detalle que no ofrecen los relatos de Antonio Carnero, Gioseppe Gamurini, Charles Alexandre de Croy y otros. De hecho, en la portada Bonours se anuncia como «du conseil de guerre, \& Capitaine entretenu de sa Majesté», y aunque se desconoce cuándo ingresó exactamente en tal órgano, el hecho de serlo antes de publicar su libro, en 1628, podría explicar su interés por este aspecto de la guerra.

De la vida y persona de Bonours se sabe poco. Su nombre apenas aparece en las fuentes coetáneas. En consecuencia, se desconocen sus motivos para escribir y editar el libro. En su dedicatoria a la infanta Isabel Clara Eugenia no menciona ninguno, pero su publicación sucede después de que varios escritores holandeses lograsen cambiar la percepción que existía sobre la caída de Ostende. En sus crónicas, empezaron por presentar la pérdida de la ciudad ya no como una clara derrota holandesa, sino como una victoria rotunda para la República y, por tanto, como un fracaso militar para el régimen archiducal (Thomas, 2020). Con su libro, Bonours pudo haber tratado de cambiar esta imagen. Es más, en un escrito anterior ya había defendido a la Monarquía Hispánica y a sus representantes en Flandes (Elías de Tejada y Spínola, 1975, pp. 75-77). Sin embargo, su posicionamiento no le impidió ser crítico con las acciones del ejército en el que servía, y sobre todo con los cabos españoles que lo dirigían. El hecho de que sus críticas se dirigieran sobre todo hacia ellos y a la rivalidad existente entre ellos y las otras naciones, sin aludir a la rivalidad existente entre cabos de una misma nación, podría ser un indicio de predisposición. No obstante, en varias ocasiones su interpretación es confirmada por fuentes inesperadas, al menos en este contexto. En efecto, durante toda la duración del sitio la guarnición holandesa

más bien lo hacía desde la situación particular de los Países Bajos. Con el tiempo, los dos grupos se reconfiguraron y se reagruparon en una facción lermista y pro-Alberto/Spínola, y otra antilermista y anti-Alberto/Spínola (Thomas, 2011, pp. 302-312). Para una interpretación reciente y novedosa del ministerio español como conjunto de personas que debían compaginar los intereses de Felipe III con los de Alberto (véase Alicia Estríngana, 2012b, p. 445). 
mantuvo informados a los Estados Generales y al Consejo de Estado en La Haya. Sus informes incluyeron las declaraciones de los desertores que llegaban a la ciudad desde las trincheras archiducales. Por razones obvias, éstos fueron interrogados sobre la situación existente en el ejército español y, en varias ocasiones, sus historias confirman, si bien en términos más generales, el relato de Bonours ${ }^{5}$.

\section{La posición particular del archiduque Alberto como capitán general}

Con la cesión de los Países Bajos a su hija Isabel Clara Eugenia, Felipe II creó una situación particular en cuanto al gobierno de estos territorios septentrionales de la Monarquía ispánica. Los archiduques se convirtieron en príncipes soberanos de estas provincias, aunque el arreglo previó una serie de mecanismos que debían impedir que los Países Bajos se alejasen de la esfera de influencia de la misma monarquía, razón por la cual los enemigos de España siempre dudaron de su independencia (Esteban Estríngana, 2021a; Thomas, 1999, pp. 48-49). Esta situación ambigua también se reflejaba en la presencia y dirección del ejército de Flandes. Al saber que sin esta fuerza militar el régimen archiducal no podía defenderse contra los ataques holandeses y franceses, se había decidido no retirarla de los Países Bajos. Para no comprometer la reputación de Alberto, se le mantuvo al frente de la capitanía general, poniéndole de esta forma en una posición ambigua: como tal estaba sometido a Felipe III, pero los intereses de Alberto como soberano no siempre coincidían con los del rey como dueño del ejército (Esteban Estríngana, 2021b).

El caso de Ostende es un buen ejemplo de la posición precaria en la que se hallaba el archiduque al ser al mismo tiempo soberano y capitán general. Por un lado, sus consejeros y militares españoles se opusieron vehemente a esta empresa, considerando lo difícil que sería tomar la ciudad. De lograrse, sería a costa de grandes pérdidas de hombres y dinero. Ellos abogaban por una campaña en el Rhin o el Mosa, o en el país de Cleves, desde donde se podía atacar la provincia de Utrecht y avanzar hasta el corazón de la República ${ }^{6}$. Por otro lado, estaba la presión de los flamencos para finalmente acometer el proyecto de expugnación. En efecto, los Estados del condado de Flandes habían insistido en que se conquistase la ciudad desde tiempos

$5 \quad$ El contenido de estas declaraciones ha llegado hasta nosotros a través del diario del secretario de Estado holandés Anthonis Duyck (Journaal van Anthonis Duyck, advokaat-fiscaal bij den Raad van State, editado por Lodewijk Mulder, 3 tomos, La Haya \& Arnhem, Martinus Nijhoff/D.A. Thieme, 1862-1866) y del informe diario Belägerung der statt Ostende. Iovrnal: Tagregister vnd eigentliche beschreibung aller gedenctwurdigsten Sachen, handlungen vnd geschichten, so inner als ausserhalb der weithberumten vnd fast vnvberwindlichen Statt Ostende in Flandern [...], S.1., 1604, que fue impreso en episodios mientras el sitio aún estaba en curso (Thomas, 2020).

BONOURs, Le memorable siege, pp. 14-15. 
de Alejandro Farnesio, porque su guarnición efectuaba salidas frecuentes para saquear poblaciones de sus alrededores y robar a los viajeros. Como consecuencia, la campiña circuncidante estaba casi totalmente despoblada y sin actividad económica (Piceu, 2008, pp. 97-183).

Al hacer su feliz entrada en Gante, el 31 de enero de 1600, los archiduques fueron recibidos con una representación teatral en la que la Virgen de Flandes se mostraba con una espina en el talón, un reclamo simbólico que resonó hasta en la misma República ${ }^{7}$. Al ser Flandes la provincia que más contribuciones fiscales generaba de todo el conjunto, este reclamo de sus diputados debía tomarse con seriedad. De hecho, después de la batalla de Nieuwpoort, el 2 de julio de 1600, y de la consiguiente retirada de Mauricio de Nassau, el archiduque pasó por Ostende para reconocer el terreno, pero decidió no asediar la ciudad. Se limitó a completar el cerco de fuertes que la rodeaba y se puso a negociar con los Estados de Flandes una contribución financiera ${ }^{8}$. Durante el otoño de 1600 y los primeros meses de 1601 los rumores de asedio aumentaron, pero los planes no se concretaron. En consecuencia, se decía que Alberto no se tomaba en serio la petición de los diputados flamencos y que sólo escuchaba a los españoles de su entorno, hundiendo así su popularidad en el país9.

Lo que no convenía emprender desde un punto de vista militar, se convirtió en la primavera de 1601 en una necesidad política para mantener la paz interior del territorio. En un intento de aumentar la presión sobre el archiduque, los Estados de Flandes empezaron a reunir material de construcción, provisiones de víveres y carros en Brujas por un valor total de 800.000 florines. Al ver que, a pesar de este esfuerzo, Alberto tampoco contemplaba un asedio en la campaña de 1601, los diputados exigieron asumir el control de la ayuda ordinaria de 50.000 florines al mes para mantener las guarniciones en su provincia, ya que consideraron que su dinero se destinaba más al pago de los gastos de la corte que al de las tropas. Incluso amenazaron con retirar su asignación ${ }^{10}$. El motín de las guarniciones de los fuertes de Santa Isabel y Grotendorst frente a Ostende, el 27 de mayo de 1601, alarmó a la provincia de Flandes. Sobre todo, creció la inquietud en Brujas, porque los fuertes vigilaban y aseguraban el camino entre esta ciudad y Ostende, poniéndola al alcance de los soldados ostendienses ${ }^{11}$. Alberto ya no pudo dejar de actuar cuando, cuatro días después, Mauricio puso sitio a Rheinberg. Entonces, el archiduque decidió responder a su vez con el

7 Journaal, t. 2, pp. 510-511.

8 Correspondance d'Ottavio Mirto Frangipani, premier nonce de Flandre (1596-1606), editada por Armand Lount, 3 tomos, Bruselas \& Roma, Palais des Académies/Academia Belga, 1924-1942, t. 3 , pp. $167-167,171,177,183$.

9 Correspondance d'Ottavio Mirto Frangipani, t. 3, pp. 224, 243-244.

10 Journaal, t. 3, p. 34; Correspondance d'Ottavio Mirto Frangipani, t. 3, p. 244. Alrededor de 1600, un florín equivalía a 0,4 escudos, y un escudo a 340 maravedíes (Maltby, 2011, pp. 11-12). Journaal, t. 3, pp. 60-61. 
sitio de Ostende con la esperanza de obligar al enemigo a retirarse ${ }^{12}$. Pero al hacerlo, sabía que Valladolid no respaldaría su movimiento. Es más, sintió la necesidad de justificarse ante Felipe III, ya que el sitio de Ostende servía menos a los intereses del monarca que a los suyos como soberano de los Países Bajos ${ }^{13}$.

Si en un principio fue la impopularidad del archiduque (entre otras razones, por no acceder a las peticiones de sus súbditos), la que propició el inicio del sitio, pronto surgió otra relación de dependencia con los flamencos que de nuevo impidió a Alberto seguir una lógica estrictamente militar. Para emprender el asedio, los Estados de Flandes habían acordado una ayuda extraordinaria de 600.000 florines, además de incrementar la ayuda ordinaria que otorgaban a 90.000 florines por mes ${ }^{14}$. Aparte de los subsidios, los Estados también pagaban por los corveen, es decir, los sueldos de los barqueros, carreteros y obreros (pionniers) necesarios para transportar los materiales y víveres desde Brujas a Ostende y para efectuar las obras de construcción en el campo, por un valor mensual de otros 40.000 florines aproximadamente. Además, en el transcurso del sitio continuaron proporcionando sumas importantes bajo la forma de subsidios extraordinarios hasta que, en la primavera de 1603, dieron a entender que la presión fiscal en el condado ya no permitía gravarlo con más imposiciones ${ }^{15}$. Para supervisar el empleo de este dinero, tanto los representantes de los Cuatro Miembros de Flandes como el comisario general de víveres del ejército de Flandes, Hendrik van Etten, asimismo presidente de la Cámara de Cuentas de Brabante, residían en el campo en sendas tiendas situadas en las cercanías del fuerte de San Alberto ${ }^{16}$.

El hecho de que los Estados de Flandes financiasen parte de los gastos ocasionados por el sitio hacía que Alberto no pudiera desistir de la empresa sin provocar malestar en sus súbditos flamencos. Ya el 24 de julio de 1601 los espías de la República en Calais informaron que el archiduque se quejaba de que había sido engañado por los «Vlamingen ende anderen» («flamencos y otros»), que le habían convencido de que Ostende podía ser tomada sólo por la fuerza de la artillería ${ }^{17}$. No obstante, Alberto no quiso levantar el asedio. Es más, a finales de septiembre, cuando ya se había perdido la esperanza de una rápida toma de la ciudad, resolvió que el sitio debía continuar durante el invierno para evitar así el descontento de los Estados de Flandes ${ }^{18}$. Después del fracaso del asalto general, el 7 de enero de 1602, los oficiales españoles insistieron varias veces en levantar el asedio para emplear los recursos en

Bonours, Le memorable siege, pp. 21-22, 30-33.

Bonours, Le memorable siege, p. 380.

Journaal, t. 3, p. 107.

Correspondance de la Cour d'Espagne, editada por Henri LonCHAY y Joseph Cuvelier, 6 tomos, Bruselas, Palais des Académies, 1923-1937, t. 1, p. 5.

Rijksarchief Brugge, Vrije registers, ${ }^{\circ} 1288$, ff. 1r-2r, 3v.

Véase las indicaciones en el mapa del campo delante de Ostende, diseñado en el verano de 1601, y conservado en Amberes, Felixarchief, Kaarten en plannen, ${ }^{\circ}$ 12/12043.

Correspondance d'Ottavio Mirto Frangipani, t. 3, pp. 268-269, 276, 278. 
una empresa militar con mayores perspectivas de éxito. Calificaban a los diputados flamencos traidores por haber arrastrado al archiduque en una aventura sin expectativas, mientras que en el Rin se estaban perdiendo las plazas ${ }^{19}$. Sin embargo, cada vez que el rumor de un levantamiento circulaba en la provincia, los Estados, asistidos por el nuncio papal Ottavio Mirto Frangipani, insistían al archiduque que debía continuar el sitio, recordándole el dinero que estaban invirtiendo en la empresa y advirtiéndole que, en caso de levantarlo, su inversión no habría servido para nada ${ }^{20}$. El miedo a una insurrección popular en la provincia de Flandes, junto a la preocupación por su reputación en el escenario europeo — Bonours habla de «honte \& escorne perpetuel» ${ }^{21}$ persuadieron al archiduque a continuar el asedio, más aún después de que la única salida alternativa del conflicto sin pérdida de reputación ni riesgo a sublevación, es decir, una tregua o al menos un alto el fuego negociado con la República, fracasara en la primavera de 1602 (Thomas, 2014, pp. 213-215). Este miedo era tal que, cuando en junio de 1602, Alberto abandonó Nieuwpoort para ocuparse de las operaciones en el Mosa, se decidió que la infanta se quedase en Gante para asegurar la lealdad de la provincia $^{22}$.

El hecho de que Alberto tuviese que mirar por sus propios intereses (y los de la infanta) como príncipe soberano de los Países Bajos, al tiempo que lo hacía por los intereses del rey de España desde su condición de capitán general, sacaba las operaciones militares del ejército del ámbito puramente estratégico-militar para introducirlas en otro mucho más politizado, donde no sólo importaban las opiniones de los militares, sino también las de los ministros flamencos y demás instancias de poder local. Así, una decisión que era buena desde un punto de vista militar no necesariamente lo era desde el punto de vista político. Alberto se enfrentaba pues a un doble problema: por un lado, los oficiales españoles no quisieron secundarle en esta lógica, y por otro, los naturales del país, particularmente la nobleza y los Estados, opinaban que el archiduque tenía demasiado en cuenta la opinión de esos «extranjeros», todo lo cual alentaba la rivalidad y antipatía entre ambos grupos ${ }^{23}$.

\section{La personalidad del capitán general}

A diferencia de los capitanes generales anteriores del ejército de Flandes, Alberto no había sido formado como militar, ni había dirigido un ejército en persona

19 Bonours, Le memorable siege, p. 243.

20 Correspondance d'Ottavio Mirto Frangipani, t. 3, pp. 278, 299, 300-301.

21 Bonours, Le memorable siege, p. 188.

22 Correspondance d'Ottavio Mirto Frangipani, t. 3, pp. 321, 324, 326. Al final el archiduque no pudo trasladarse a Bruselas porque no se recuperó suficientemente, y se quedó en Gante con la infanta (Esteban Estríngana, 2012a, p. 291). Journaal, t. 3, pp. 39-40. 
hasta que en 1596 llegó a Flandes como gobernador general (Parker, 1972, p. 281). Tampoco mostraba gran talento para lo militar. «[Alberto] sin duda es mejor para la paz, que para la milicia», observó el nuncio papal Guido Bentivoglio en el retrato del archiduque incluido en sus Relaciones ${ }^{24}$. Alberto había sido preparado para una carrera eclesiástica como cardenal y arzobispo de Toledo, y sólo después del fallecimiento de su hermano Ernesto, en 1595, Felipe II le consideró para gobernar los Países Bajos (Duerloo, 2012, pp. 30-41). De hecho, no renunció a sus beneficios eclesiásticos hasta julio de 1598, dos meses antes de viajar a la Península Ibérica para casarse con la infanta (Duerloo, 2012, pp. 52-53).

En Madrid pronto surgieron dudas sobre sus capacidades militares, sobre todo después de la batalla de Nieuwpoort en la que sufrió una derrota contra las tropas de Mauricio de Nassau. En esta batalla, el archiduque no cayó prisionero por poco, recibiendo una herida de alabarda, mientras que su comandante en jefe, el capitán general de caballería Francisco de Mendoza, era capturado por el enemigo junto a otros oficiales del ejército ${ }^{25}$. Ya en el consejo de Estado del 1 de agosto de 1600 surgió la idea de enviarle «otra persona de mucha calidad» que pudiese mandar el ejército «en ocasión de neçesidad». El mismo Felipe III no tardó en aprobar esta idea, dio orden de redactar una lista de candidatos al puesto y mandó informar del plan a su embajador en Bruselas, Baltasar de Zúñiga. Apenas dos semanas después, el 13 de agosto, el consejo estaba discutiendo candidatos, no sólo para la lugartenencia del ejército, sino también para el puesto de mayordomo mayor de la infanta ${ }^{26}$. Es más, en el transcurso de 1601 en Valladolid se discutió varias veces la opción de reincorporar los Países Bajos a la monarquía y de «poner a mis hermanos en parte donde estuviessen con autoridad y seguridad $»^{27}$. El asunto de un asesor militar se trató en varias reuniones entre los veranos de 1601 y 1603 (Esteban Estríngana, 2012a y 2021b).

También en los Países Bajos surgieron con cierta frecuencia rumores de que Felipe III tenía la intención de «retirar» a los archiduques. El 18 enero de 1602, menos de dos semanas después del asalto general fracasado, Frangipani informó a Roma que se murmuraba que podían abandonar los Países Bajos y convertirse en virreyes de Portuga $^{28}$. En abril de 1603 señaló que en Bruselas se daba por seguro que el gobierno de Flandes no gustaba a Madrid ${ }^{29}$. En octubre del mismo año se decía que los archiduques estaban a punto de regresar a España ${ }^{30}$. En enero de 1604, la llegada

24 Erycius Puteanus, Relaciones del cardenal Bentivollo, Nápoles, sin impresor, 1631, p. 139.

25 Henrick Van Haestens, De bloedige ende strenge belegeringhe der stadt Oostende in Vlaenderen, Leiden, Henrick van Haestens, 1613, pp. 23-41.

26 Consultas del Consejo de Estado, 1600-1603, editadas por Mariano Alcocer y Martínez, Valladolid, Casa Social Católica, 1930, pp. 33-37 y pp. 60-64.

27 Correspondance de la Cour d'Espagne, t. 1, p. 77.

28 Correspondance d'Ottavio Mirto Frangipani, t. 3, pp. 299-300.

29 Correspondance d'Ottavio Mirto Frangipani, t. 3, p. 379.

30 Correspondance d'Ottavio Mirto Frangipani, t. 3, p. 438. 
a Bruselas del condestable de Castilla, Juan Fernández de Velasco, que luego viajaría a Londres para negociar la paz con Inglaterra, provocó el rumor de que el verdadero propósito de su viaje era convencer a los archiduques de abandonar los Países Bajos $^{31}$. Este tipo de rumores continuos debieron de contribuir a minar la autoridad de Alberto y, en cualquier caso, demuestran que, al menos los españoles de la corte o del ejército, le tuvieron poco respeto, ya que fueron ellos quienes aparentemente los propagaron.

Alberto no compensaba las dudas sobre su posición como capitán general con una actitud firme de comandante. Le faltaban las cualidades comunicativas que eran necesarias para dar la impresión de un liderazgo firme y para motivar a sus oficiales y soldados. «[Alberto] habla poco, al modo que lo hazen los Principes Austriacos, y despacio, por su propia costumbre natural», notó Bentivoglio ${ }^{32}$. Evitaba expresar sus sentimientos personales bajo cualquier circunstancia, «sin que se le pueda conocer jamas en el rostro (que siempre le tiene sereno, y con ygualdad), commocion ninguna que discurra por su ánimo» ${ }^{33}$. Esta actitud se reflejaba también en su manera de ejercer el mando en Ostende. Durante la primera reunión del consejo de guerra, después de que las tropas se instalaran en los alrededores de la ciudad, el 7 u 8 de julio de 1601, Alberto se limitó a escuchar las opiniones de sus cabos sobre la táctica a seguir, para luego partir a Brujas sin comunicar su propio parecer, discutir las posibilidades o tomar una decisión ${ }^{34}$.

Su actuación en esta ocasión revela otro de sus defectos: la falta de resolución. Alberto no regresó al campo para dar las primeras órdenes hasta algunos días después, el 10 de julio. Una indecisión que tuvo consecuencias: las tropas no pudieron empezar las operaciones defensivas y tuvieron que soportar el cañoneo de la ciudad, limitándose a buscar protección en las dunas ${ }^{35}$. En su ausencia ya habían surgido rumores tanto en la ciudad como en el propio ejército archiducal, de que su maniobra ante Ostende no era más que una diversión para obligar a Mauricio de Nassau a levantar el sitio de Rheinberg. Como resultado, comenzaron a circular los primeros chistes que se burlaban del archiduque, minando así su autoridad entre los soldados comunes $^{36}$. Peor aún, según el nuncio papal su «falta de espíritu» para tomar decisiones era la causa de los muchos errores cometidos durante los primeros meses del $\mathrm{sitio}^{37}$. En consecuencia, las dudas sobre su capacidad también empezaron a manifestarse en el campo. A mediados de noviembre, un desertor informaba al comandante

31 Correspondance d'Ottavio Mirto Frangipani, t. 3, p. 451.

32 Puteanus, Relaciones, p. 138.

33 Puteanus, Relaciones, p. 139.

34 Bonours, Le memorable siege, p. 112.

35 Belägerung, f. 3r.

36 Bonours, Le memorable siege, pp. 112-113.

37 Correspondance d'Ottavio Mirto Frangipani, t. 3, p. 269. 
inglés Francis Vere que los capitanes españoles estaban convencidos de que «l'Archiduc n'est bon a rien que pour faire perdre des soldats \& diminuer le nombre des gens de bien \& d'honneur, parce qu'il n'entend rien au faict de la guerre, ce qui ennuye extremement les soldats qui y sont $\aleph^{38}$.

\section{La dinámica del alto mando}

Durante el sitio de Ostende, Alberto no estuvo presente a todas horas. En los días previos supervisó los preparativos desde Brujas. El 5 de julio de 1601 se desplazó al fuerte de Oudenburg, punto de reunión para todas las unidades, donde inspeccionó a las tropas antes de dar la orden de marcha. Parte del ejército se dirigió al fuerte de Bredene, situado en el lado oriental de la ciudad. El mismo archiduque condujo la segunda parte hacia el fuerte de San Alberto, en el lado occidental. Mientras sus tropas se instalaban en las dunas, se acercó a la ciudad en compañía de poca gente para reconocer las fortificaciones y comprobar la precisión de un mapa que le habían enviado el día anterior ${ }^{39}$.

En días posteriores, Alberto viajó entre el campo, el fuerte de Oudenburg, donde se alojó hasta el 26 de julio, y la ciudad de Brujas, donde residía la infanta, debido a que el fuerte de San Alberto, cuyas instalaciones fueron quemadas por el enemigo durante la campaña de 1600 , tuvo que ser reparado antes de poder dar alojamiento a la corte ${ }^{40}$. Una vez instalado el archiduque en el fuerte, pasó más tiempo en el campo, aunque se ausentaba periódicamente para almorzar con la infanta en Nieuwpoort, adonde ésta se había trasladado el 28 de julio ${ }^{41}$. Solía dormir en el campo hasta que el 13 de noviembre de 1601 las casas del fuerte se incendiaron por el descuido de una criada ${ }^{42}$. Desde entonces, residió en Nieuwpoort y visitó el campo cada dos días, alojándose en la cabaña del conde de Solre, su caballerizo mayor ${ }^{43}$; en noviembre se ausentó diez días para organizar el alzamiento del cerco de 's-Hertogenbosch ${ }^{44}$. Permaneció en Nieuwpoort hasta junio de 1602, cuando decidió trasladarse a Gante para estar más cerca al teatro de operaciones en el este del país. En el otoño hizo planes

38 Histoire, f. $48 \mathrm{v}$.

39 Bonours, Le memorable siege, p. 102.

40 Charles Alexandre de Croy, Memoires gverriers de ce qv'y c'est passé avx Pays Bas, Amberes, Hiëronymus Verdussen, 1642, pp. 22-24. Véase la anotación al lado izquierda del fuerte de San Alberto, posteriormente introducida en el mapa hecho el 16 de julio de 1600 por un espía de la República, conservado en la Bibliothèque Royale de Belgique, Cartes et plans, $\mathrm{n}^{\circ}$ IV 10.125: «Ceste place est le lieu aplany ov lennemy estoit premierement trencé, et logé selon temps que les fortz d'Elizabet, et le fort d'Albert ont estes mis en deffensse pour y loger leurs gens dedans».

41 Croy, Memoires, pp. 26-35.

42 Belägerung, f. 14v; Bonours, Le memorable siege, pp. 136*-137*.

43 Correspondance d'Ottavio Mirto Frangipani, t. 3, p. 256; Bonours, Le memorable siege, p. 137*.

Croy, Memoires, pp. 41-42. 
de regresar a Ostende, pero finalmente no viajó hasta allí en $1602^{45}$. Sólo volvió a aparecer en el campo en abril de 1603 para visitar las fortificaciones del pólder que se había conquistado poco antes ${ }^{46}$. El resto del tiempo se dedicó a los asuntos de gobierno en Bruselas, o a la coordinación de las operaciones ofensivas y defensivas en otras regiones del país.

Otro factor importante que incidía sobre la disponibilidad de Alberto como comandante del asedio era su delicada salud. El archiduque padeció gota, enfermedad que frecuentemente le impedía estar con el ejército en campaña. En febrero de 1602 se encontraba enfermo en Nieuwpoort, aunque esta vez su indisposición se debió a una caída en su habitación, tras haberse dormido durante la oración ${ }^{47}$. A inicios de junio, estuvo de nuevo «tenant le lict» ${ }^{48}$. El 19 de julio, el nuncio informó a Roma que Alberto se hallaba en Gante recuperándose, aunque todavía muy débil y sin poderse mover, por lo que la infanta había hecho remodelar el antiguo palacio de los condes de Flandes ${ }^{49}$. A los consejeros de Estado en Madrid no les quedó más que constatar, en su reunión del 26 de noviembre, «el daño que se siguio de no poder salir el Sr. Archiduque en campaña el verano pasado por su indispusiçion». Aprovechaban la ocasión para repetir al rey su consejo de enviar a una persona de su confianza a Flandes para dirigir el ejército ${ }^{50}$.

Desde un principio, la indisponibilidad del archiduque como capitán general, por su ausencia física delante de Ostende, bien por su mala salud o bien por las dos cosas a la vez, retrasó y complicó la toma de decisiones, en ocasiones con consecuencias graves. Por ejemplo, Alberto no estuvo presente - y, por tanto, no pudo dar órdenes - los días 16 de julio de 1601 y siguientes, cuando el recién llegado Francis Vere se enterró con sus ocho compañías de ingleses en el pólder frente a la contraescarpa occidental para así dispersar las tropas y asegurarse la zona por donde la guarnición sacaba la tierra para la reparación de sus fortificaciones (figura 1). Allí erigió una serie de revellines y reductos para proteger su posición contra los cañones archiducales (Thomas, 2004b, p. 85). Permitir que los asediados ocupasen esta zona fue un error gravísimo, ya que esta parte de la muralla era la menos fortificada de todas ${ }^{51}$. De hecho, Alberto se dio cuenta del error, porque enseguida se dispuso a mudarse al fuerte de San Alberto lo más rápido posible, «pour auec sa presence donner l'ordre le plus brief \& requis pour l'aduancement de ce siege $»^{52}$.

\footnotetext{
45 Correspondance d'Ottavio Mirto Frangipani, t. 3, pp. 344, 346, 349.

46 CROY, Memoires, pp. 95-96.

47 Correspondance d'Ottavio Mirto Frangipani, t. 3, p. 303.

48 Croy, Memoires, p. 45.

49 Correspondance d'Ottavio Mirto Frangipani, t. 3, p. 326.

$50 \quad$ Consultas, p. 257.

51 Journaal, t. 3, pp. 92-93.

52 Croy, Memoires, p. 50.
} 
Figura 1. Ostenda Obsessa et Capta Ab Alberto et Isabella

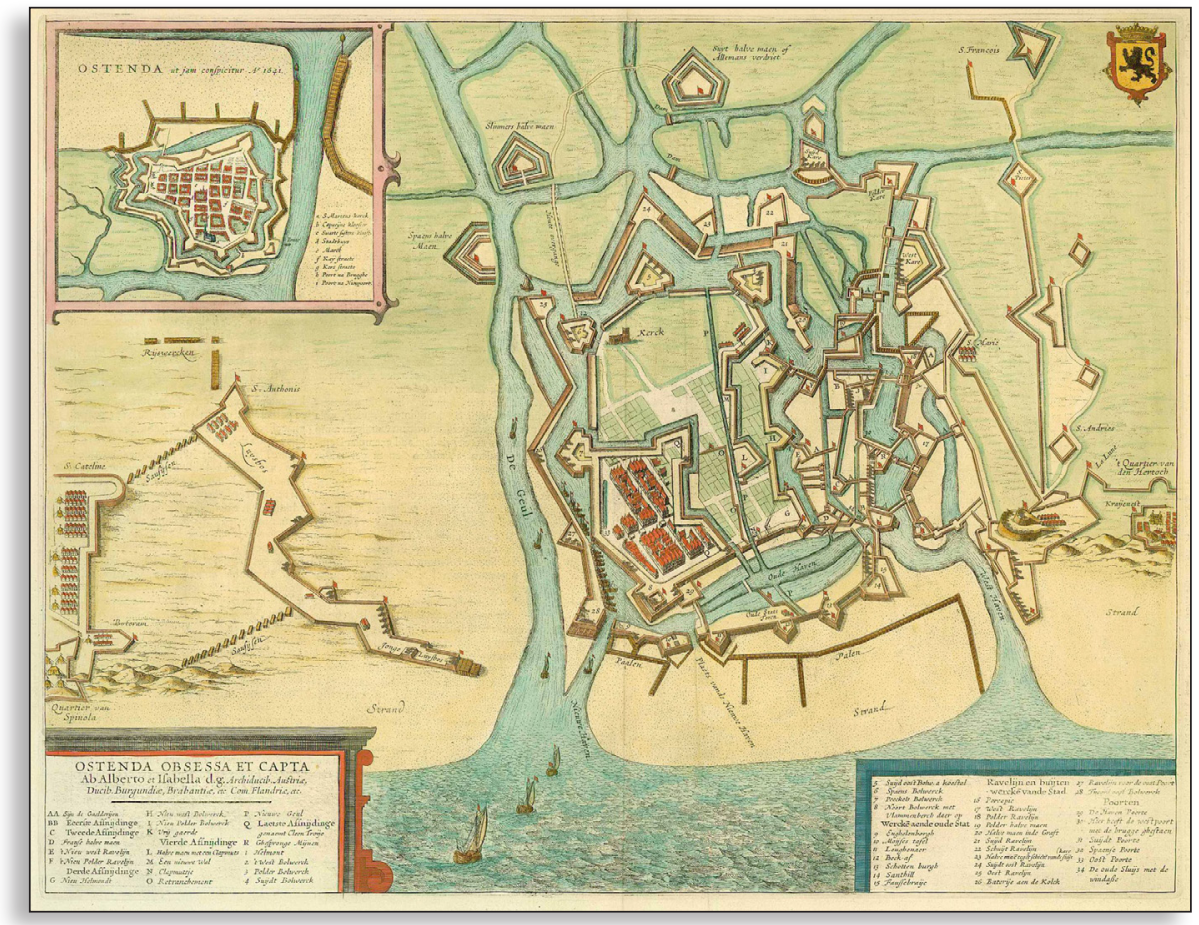

Fuente: Originalmente publicado en Joan Blaeu, Novum ac magnum theatrum urbium Belgicae liberae ac foederatae, vol. 1, Amsterdam, 1649.

A la izquierda se encuentra el Cuartel de Bredene con el dique de Bucquoy («Luysbos» y «Jonge Luysbos»), a la derecha se ve una pequeña parte del Cuartel de San Alberto. Los edificios que se mencionan en el texto son: Helmont $\left(n^{\circ} 1\right)$, Bastión del Oeste $\left(n^{\circ} 2\right)$, Bastión del Pólder ( $\left.n^{\circ} 3\right)$, Schottenburg $\left(n^{\circ} 13\right)$, Sandhille ( $\left.n^{\circ} 14\right)$, Faussebraye de Sandhille $\left(n^{\circ} 15\right)$, Porcespic $\left(n^{\circ} 16\right)$, la Puerta del Oeste ( $\left.{ }^{\circ} 30\right)$ y La Nova Troia (Q). La Gran Plataforma se encuentra a la derecha, frente al puerto de la ciudad. Las fortificaciones de Vere en el pólder se sitúan entre los bastiones Suijd Kare, Polder Karé y West Karé. El río Geule da acceso al puerto nuevo a la altura de la Spaens halve Maen («media luna española») y el Revellín del Este ( $\left.n^{\circ} 25\right)$. El Dique Verde se encontraba en el lugar de la Gran Plataforma. Los otros fuertes y reductos mencionados en el texto no se encuentran en este mapa.

Fue probablemente en estos días cuando el archiduque decidió dejar el mando cotidiano en manos del maestre de campo Agustín Messía, que ya gobernaba el Cuartel de San Alberto - el de Bredene lo dirigía el conde Frederick van den Ber$\mathrm{gh}^{53}$. El 29 de julio los espías de la ciudad efectivamente señalaron que Messía era el «Generael vanden leger vanden Ertshertoge» («general del éjercito del archiduque»), pero es posible que Messía ya ejerciera esta función antes ${ }^{54}$. Bonours describe cómo a mediados de julio Messía desempeñaba «par tout le deuoir que requeroit l'office qu'il exerçoit», y el 23 de julio se le señaló inspeccionando el Cuartel de Bredene, algo que

53 Carnero, Historia, p. 482.

54 Journaal, t. 3, p. 113. 
antes había hecho Alberto ${ }^{55}$. Los prisioneros capturados por la guarnición durante el ataque que Vere hizo a las trincheras españolas el 27 de julio, y en el que perecieron más de seiscientos soldados del ejército archiducal, contaron que Messía se había herido en la mano, lo cual indica que se encontraba en el lugar de la acción, mientras que el archiduque había contemplado el ataque desde una duna en las cercanías del fuerte de Santa Clara ${ }^{56}$.

La designación de Messía cambió en cierto modo la dinámica del alto mando en el ejército sitiador. Aparentemente, en ausencia de Alberto los oficiales mayores seguían reuniéndose en una especie de consejo de guerra. Como el archiduque prefirió no delegar el mando completo sobre el asedio a Messía, o al menos no las decisiones estratégicas principales, éste, al terminar las reuniones, trasladaba los pareceres de los cabos al archiduque para que tomara dichas decisiones. A continuación, Messía se las comunicaba a los involucrados. Así transcurrió, por ejemplo, el consejo de guerra de inicios de agosto de 1601, en el cual se discutió la construcción de ciertas obras en el pólder ${ }^{57}$.

La nueva forma de proceder en ausencia de Alberto provocaba más retraso en la toma de decisiones y a veces causó la pérdida de oportunidades inesperadas. Cuando el 26 de septiembre un temporal destrozó los fundamentos del baluarte llamado Zandhill («Montaña de arena») y de la falsabraga llamada Faussebraye, y abrió una brecha en la muralla, algunos cabos sugirieron lanzar un ataque con mil soldados. Sin embargo, otros se opusieron, y se tuvo que esperar la decisión final de Alberto. Entretanto, la guarnición consiguió tapar la brecha en una sola noche, perdiéndose así la oportunidad ${ }^{58}$. En otros casos, la comunicación indirecta con sus oficiales causó un retraso innecesario. A mediados de septiembre, el archiduque concibió el plan de tapar la entrada al puerto viejo con miles de sacos terreros que había hecho juntar en el condado de Flandes. Al ser consultados, la mayoría de sus oficiales consideró el plan como «inutile; \& si elle n'eut eté approuuee du Prince, ridicule», pero Alberto insistió. Llegados los sacos al campo, fueron llenados de arena y llevados a la entrada del puerto por dos mil soldados, algunos de los cuales, con «la conniuence de maint Officier, se moquant de tout cela», y en vez de tirarlos al agua, los vaciaban para quedarse con el saco. En los días siguientes, la marea simplemente arrastró los demás ${ }^{59}$. Toda la operación había costado dinero, hombres y tiempo sin ningún resultado tangible. Un consejo en presencia del archiduque posiblemente hubiera podido convencerlo de no proseguir con este plan. 
Aparte de no agilizar la toma de decisiones en ausencia del archiduque, el cambio originó dos problemas estructurales importantes. Primero, influyó en la dinámica de las reuniones de la oficialidad. Como demuestra el primer consejo, en presencia del archiduque los oficiales mayores se limitaban a dar su parecer, reforzando su discurso con estos o aquellos argumentos. Después de que cada uno hubiera intervenido, Alberto se ausentaba para reflexionar su decisión. En la nueva configuración, que era mucho más una reunión entre iguales, las discusiones no siempre se desarrollaban de forma civilizada. En la reunión celebrada a inicios de agosto, por ejemplo, surgió un conflicto entre el valón Catrice, que quería más medios para hacer avanzar sus acercamientos al Dique Verde, y los cabos españoles, que insistían en construir una trinchera entre las dunas y el canal de abastecimiento para detener las salidas del enemigo al pólder. Messía intentó convencer a Catrice y le propuso construir acercamientos en un lugar más conveniente, pero éste persistió en su empeño. En su opinión, abandonar la obra sería «non seulement chose dommageable, mais honteuse et ridicule». Se opuso a la prioridad que se quería otorgar a las trincheras en el pólder y dio a entender a los comandantes españoles, «par paroles aigres, \& reprochantes, l'erreur qu'ilz auoient commis, permettant a Veer de fortifier, a leurs yeux [el pólder]». Es más, «il leur remit auant, par inuectiue, leur tardité, \& lenteur accoutumee ${ }^{60}$. En ausencia del archiduque y, por tanto, de un árbitro, no hubo nadie que contuviera las diferencias entre los oficiales mayores, las cuales rápidamente crearon una atmósfera cargada y estimularon la rivalidad interna, sobre todo entre españoles y naturales.

Segundo, el hecho de que Alberto ya no presidiese todos los consejos de guerra hizo que algunos oficiales se dirigieran directamente a él al objeto de conseguir carta blanca para sus planes particulares, colocando así al consejo ante un hecho consumado. Esto, a su vez, provocaba el malestar de los oficiales de opinión contraria, ya que su parecer ni siquiera era tomado en consideración. De esta forma Charles de Longueval, conde de Bucquoy, obtuvo en enero de 1602 permiso para terminar un fuerte en el Cuartel de Bredene — que estaba dirigiendo desde el 19 de agosto del año anterior - situado frente a la entrada al nuevo puerto que los asediados habían hecho por el río Geule. Los cabos españoles se habían opuesto a tal empresa y habían logrado parar la obra, pero Bucquoy viajó a Nieuwpoort para convencer al archiduque. Su acción provocó el descontento de los maestres de campo españoles y aumentó la «discorde, \& dissention» ${ }^{61}$.

En junio de 1602, cuando Alberto decidió moverse de Nieuwpoort a Gante para desde allí contrarrestar mejor los planes del príncipe de Orange, dejó el mando del sitio en manos del maestre de campo Juan de Ribas, superintendente de la milicia en el condado de Flandes, ya que Messía había renunciado al puesto por motivos de

60 Bonours, Le memorable siege, p. 154.

61 Belägerung, ff. 4v, 10v; Bonours, Le memorable siege, pp. 176*-179*. 
salud (Esteban Estríngana, 2021b, nota 38) ${ }^{62}$. Esta vez sí le dio amplios poderes tanto para continuar los trabajos ya iniciados como para emprender nuevos. El consejo de guerra le asistiría en sus decisiones. El archiduque esta vez sólo pidió que le pusiese al tanto de todo ${ }^{63}$. A estas alturas del asedio, sin embargo, la rivalidad entre los cabos y sus unidades había alcanzado niveles casi insuperables.

\section{La rivalidad entre las naciones}

Desde su creación, el ejército de Flandes estaba formado por soldados procedentes de los diferentes territorios de la Casa de Habsburgo en Europa. En la infantería, el componente más importante, los españoles, italianos, borgoñones, valones y alemanes luchaban codo con codo, a veces asistidos por tropas procedentes de otras regiones europeas. Sin embargo, las diferentes «naciones», como se les llamaba en las fuentes coetáneas, no estaban al mismo nivel. Los tercios españoles, integrados por efectivos que solían haber recibido entrenamiento militar antes de llegar a los Países Bajos, formaban la columna vertebral del ejército. Esta era una de las razones por las que las ordenanzas militares reservaban a las unidades españolas las posiciones de vanguardia. Los tercios italianos les seguían en estatus. Los regimientos borgoñones y valones, en este orden, ocupaban una posición bastante inferior, siendo considerada esta última infantería como «menos que mediocre» por el hecho de que, muchas veces, sus efectivos carecían de formación miliar previa. También ellos fueron organizados en tercios en 1602, durante el sitio de Ostende. Finalmente, los regimientos alemanes eran concebidos como poco fiables y de poca utilidad en el combate (González de León, 2009, p. 97).

En Ostende, la jerarquía entre los tercios y regimientos se reflejaba en la manera en que el ejército había ocupado el terreno. Al principio Alberto planificó asediar la ciudad desde el noreste y el suroeste. En el noroeste se encontraba el mar, y la región al sur y sureste era una zona demasiada pantanosa como para emprender acción bélica alguna. La atravesaba una densa red de riachuelos y lagunas que crecían y bajaban de seis a seis horas, al ritmo de las mareas. Además, la ciudad no tenía ninguna puerta hacia ese lado, lo cual impedía que la guarnición pudiese hacer salidas en esa dirección. Finalmente, desde 1599 Ostende quedó rodeada por una cadena de fuertes que debían impedir las frecuentes correrías de su guarnición en la campiña flamenca, y cuatro de ellos, los de Santa Isabel, Grotendorst, Santa Clara y San Miguel (o Colombière), con sus respectivos reductos, se encontraban en esta zona (Lombaerde, 2004b, pp. 56-57). Esta cadena de fuertes y reductos debía ser suficiente como para cerrar el cerco por este lado de la ciudad.

62 Correspondance d'Ottavio Mirto Frangipani, t. 3, p. 321.

63 Bonours, Le memorable siege, pp. 226-227. 
Para ocupar las dos zonas accesibles, el ejército se dividió en dos. Al noreste fueron enviados el tercio italiano de Alfonso Dávalos, el regimiento alemán del conde Frederick van den Bergh, y los regimientos valones de Charles de Lalaing, barón de Hachicourt, y de Eustache d'Ognies, señor de Gruson, junto con tres compañías de caballería $^{64}$. Allí se instalaron en las dunas alrededor del fuerte de Bredene, que dio su nombre a este cuartel, evitando de esta forma convertirse en el blanco de la artillería enemiga. Como esta zona estaba separada de la ciudad por el río Geule, de considerable profundidad y difícil de cruzar incluso con marea baja, la función principal de estas tropas, además de cañonear la ciudad, era proteger la playa y el costado norte de los sitiadores contra posibles desembarques del enemigo o intentos de levantamiento del sitio desde Zelanda. Es probable que la casi imposibilidad de asaltar la ciudad desde este lado fuese la razón por la que ningún tercio español recibiera alojamiento en este cuartel.

Los mencionados tercios fueron enviados al lado suroeste de la ciudad, llamado el Cuartel de San Alberto. Se trataba de los de Luis de Villar, Juan de Ribas y Jerónimo de Monroy. Estaban acompañados del regimiento borgoñón de Christophe de Rye, marqués de Varambon, de los regimientos valones de Charles II de Gavre, conde de Frésin, y del coronel Nicolás Catrice, y del regimiento alemán de Florent conde de Berlaymont, junto con algunas compañías libres de valones y alemanes, las compañías de lanceros y arcabuceros de la guardia del archiduque, y el resto de la artillería bajo el mando de Luis de Velasco ${ }^{65}$. También del lado suroeste las tropas buscaron la protección de las dunas contra los cañones del enemigo. Los tercios ocuparon la franja situada frente al puerto, por donde se pensaba atacar la ciudad. Detrás de ellos se instalaron los regimientos de Varambon, Frésin y Catrice. El regimiento alemán, formando la retaguardia del ejército, ocupó la posición más alejada de la ciudad. La corte se acomodó en los alrededores del fuerte de San Alberto, cuyas instalaciones habían sido quemadas por el enemigo en la secuela de la batalla de Nieuwpoort y que estaban siendo reparadas a alta velocidad ${ }^{66}$. En los días siguientes, el cañoneo de la ciudad forzó a estas tropas a retroceder y a adentrarse más en las dunas, e incluso allí no estuvieron a salvo ${ }^{67}$. Debido a la concentración de tantos soldados en un espacio reducido, las balas del enemigo causaron un alto número de muertos. Los días $10 \mathrm{y}$ 11 de julio se organizó un reacomodo de las unidades en las dunas y el pólder, situado entre éstas y el canal por donde llegaban las provisiones desde Brujas, que corría paralelo a la costa y pasaba por el fuerte de Santa Isabel. Sólo entonces se decidió que los regimientos de Berlaymont y Frésin se moviesen a la llanura detrás de las

64 Bonours, Le memorable siege, p. 99.

65 Bonours, Le memorable siege, pp. 99-100.

66 Bonours, Le memorable siege, pp. 102-103.

67 Belägerung, f. 3r. 
mencionadas dunas. En la nueva posición, sin embargo, quedaban a plena vista de la artillería enemiga, por lo cual los soldados tuvieron que cavar trincheras y hacer parapetos para protegerse ${ }^{68}$.

Al volver al campo después del primer consejo de guerra, el 10 de julio de 1601, Alberto comunicó su plan de ataque, que era un asalto a la ciudad vieja, propuesto por los maestres de campo españoles y, en menor medida, por Catrice, y que en realidad era su segunda opción, ya que la primera había sido un ataque por el lado del pólder. Al anochecer, las diferentes unidades cooperaron en la construcción de una trinchera a unos trescientos pasos (ciento noventa metros) de la contraescarpa, entre las dunas y el pólder. Tres compañías de Monroy y doscientos soldados borgoñones se dedicaron a este trabajo, al tiempo que quinientos alemanes cavaban un foso al pie de las dunas. Mientras, Varambon tenía el resto de los borgoñones y alemanes en alerta para responder a cualquier salida de la guarnición. Catrice, a su vez, fue enviado con trescientos valones a las dunas para reconocer las posibilidades de construir acercamientos en dirección de Zandhill ${ }^{69}$. Este baluarte formaba parte del sistema de defensa en la parte occidental de la playa, junto con el de Helmont («Boca del infierno»), el revellín llamado Porcespic («Puerco espina»), por los numerosos salientes en su base) y la falsabraga al pie de Zandhill. Juntos, controlaban la entrada al puerto que, a su vez, daba acceso a la ciudad vieja. En pocos días, tanto los hombres adjudicados a Monroy como los de Catrice erigieron dos plataformas para instalar dos baterías ${ }^{70}$.

En los días y semanas siguientes, esta forma de trabajo combinado continuó. La primera salida de la guarnición con mil doscientos hombres en dirección de las obras de los sitiadores, el 13 de julio, fue rechazada por españoles, borgoñones, valones y alemanes ${ }^{71}$. Dos semanas después, la primera salida del gobernador Vere fue contestada de la misma forma ${ }^{72}$. En cambio, a mediados de agosto de 1601 la rivalidad entre las naciones ya se manifestaba abiertamente, como consta de una carta del nuncio Frangipani, que residía con la infanta en Nieuwpoort, al cardenal Pietro Aldobrandino $^{73}$. En consecuencia, cada tercio y regimiento se ocupaba de sus propias obras, algo que Varambon y Frésin habían pedido «pour leur propre reputation, $\&$ de leur nation ${ }^{74}$. Cuando alrededor del 20 de agosto Messía propuso añadir dos compañías de españoles a los borgoñones que Varambon tenía listos para asaltar una trinchera inglesa en el pólder y utilizarla contra la ciudad, su mera sugerencia fue

68 Bonours, Le memorable siege, p. 105.

69 Bonours, Le memorable siege, pp. 114-115.

70 Bonours, Le memorable siege, p. 124.

71 Belägerung, f. 3r; Bonours, Le memorable siege, pp. 126-128.

72 Bonours, Le memorable siege, pp. 131-137.

73 Correspondance d'Ottavio Mirto Frangipani, t. 3, p. 257.

74 Bonours, Le memorable siege, p. 153. 
suficiente para que Varambon desistiera del plan. No quería que los españoles participasen en su operación ${ }^{75}$. Por otro lado, cuando Bucquoy pidió el ya mencionado permiso para su fuerte frente al río Geule, con el argumento de que la ciudad sólo se podía tomar bloqueando su abastecimiento, uno de los maestres de campo españoles, cuyo nombre Bonours «pour respectz» no menciona, en un momento de descuido - «s'oubliant par trop en son discours», dice Bonours - exclamó decepcionado «Qu'il vaudra mieux pour le Roy, qu'Ostende demoura encore dix ans a prendre, que de veoir adjuger l'honneur de sa reduction a vn autre que de sa nation ${ }^{76}{ }^{7}$.

Uno de los sentimientos que más alimentaban esta rivalidad era el «honor» que se podía obtener como oficial o soldado mediante una acción bélica sonada y valerosa. La manera en la que los tercios y regimientos se instalaron frente a la contraescarpa occidental ilustra perfectamente esta necesidad de procurar el honor de la propia unidad. Desde el primer momento, cada uno de los maestres de campo y coroneles destacados en el Cuartel de San Alberto soñó con tener el honor de que su unidad fuese la primera en aparecer en la muralla del enemigo y forzar una entrada a la ciudad. Pero se debe entender que «obtener honor» mediante una acción o logro importante y/o heroico en el campo de batalla era más que una cuestión de orgullo personal o colectivo. Lo que uno lograba batallando - una acción individual en el caso de un soldado, un logro de la unidad en el de los oficiales que las gobernaban- determinaba en buena medida las posibilidades de lograr una promoción o un sobresueldo. No pocas veces los héroes de una acción militar eran presentados al capitán general por sus oficiales y recibían a continuación una remuneración pecuniaria o una promoción ${ }^{77}$. Los oficiales, por su parte, mejoraban su posición en la carrera eliminatoria hacia los puestos del alto mando del ejército (Esteban Estríngana, 2012a; Parker, 1972, pp. 118-123; González de León, 2009, pp. 62-88). Así se entienden mejor los conflictos que surgían en el ejército - y no sólo en Ostende - siempre que se decidía el lugar que cada tercio o regimiento ocuparía en una marcha o batalla, sobre todo cuando la posición más peligrosa, y por tanto más honrosa, no se adjudicaba a los españoles, tal y como las ordenanzas reales prescribían (Esteban Estríngana, 2012A).

Esta competencia por ocupar el lugar más «honroso» también jugó su papel en Ostende. Con el fin de obtener «honor», tanto Catrice como Monroy ocuparon la parte de las dunas más cercana a los bastiones de Zandhill y Helmont para iniciar la construcción de plataformas y acercamientos en dirección al puerto y a la muralla, según había decidido Alberto. Monroy logró terminar la construcción de una batería de doce cañones, llamados por los sitiadores Los Doce Apóstoles, con los que disparaba contra Zandhill y la ciudad vieja; después de su muerte, el 27 de julio, su

75 Bonours, Le memorable siege, p. 172.

76 Bonours, Le memorable siege, p. 179*.

77 Para Ostende después de la toma, véase Bonours, Le memorable siege, p. 598. 
tercio fue concedido al portugués Simon Antúnez, quien empezó la construcción de un reducto llamado Valdés en el pólder al lado de las dunas ${ }^{78}$. Por el lado del mar, los acercamientos de Catrice avanzaron tanto que pronto se vió en buena posición para arriesgar un asalto al mismo bastión.

El hecho de que, según Bonours, fuera un «natural» quien estaba haciendo mayores progresos en el acercamiento a la muralla del enemigo provocó que los maestres de campo intentaran detener sus obras mediante peticiones a Messía y durante los consejos de guerra. Ellos querían que se diese prioridad a la ampliación del reducto de Valdés y de sus trincheras frente a la contraescarpa, desde donde pensaban asaltar la cortina de la ciudad. Como no lo lograron, hicieron correr el rumor de que se estaba perdiendo una buena ocasión para tomar la ciudad. Esto provocó el reproche de Catrice de que, si tan importante era el pólder para forzar acceso a la ciudad, mejor hubiera sido que no hubieran permitido a Vere alojarse allí y fortificar su posición ${ }^{79}$. Después de que Catrice cayera herido de una bala en la cabeza, el 7 de septiembre, los españoles incluso rehusaron continuar sus obras y las dejaron abandonadas ${ }^{80}$. En los días siguientes, el mar y el cañoneo de la ciudad las dañaron; daños que no se repararon hasta que Alberto, en una visita a las trincheras, se percató de la negligencia, y les ordenó ocuparse de ellas ${ }^{81}$.

Aparentemente, Alberto intentó solucionar el conflicto autorizando a los cabos españoles a terminar el reducto de Valdés. Con el apoyo de Messía, Antúnez construyó luego otro al lado, al que llamó San Agustín en su honor. Varambon y Frésin iniciaron a su vez la construcción de un cuarto reducto al borde del canal de abastecimiento. En algo más de una semana erigieron las bases, aunque con mucha pérdida de gente por el cañoneo de los asediados. Cuando además el 20 de agosto de 1601 la marea afectó gravemente la construcción, Messía quiso abandonar la obra, pero tanto borgoñones como valones insistieron en mantener el reducto y acabaron terminándolo ${ }^{82}$.

Finalmente, Catrice también terminó en el pólder. Ya el 10 y 11 de julio, Alberto había trasladado el regimiento de van den Bergh al fuerte de Santa Clara, y cuando tres meses después éste salió del sitio para dirigir el ejército en Brabante, lo sustituyó por el de Catrice, que había vuelto al campo tras curarse de su herida. El tercio italiano de Dávalos, igualmente trasladado del Cuartel de Bredene al de San Alberto, obtuvo un lugar entre españoles y naturales ${ }^{83}$. Para mediados de julio de 1601, cada nación ocupaba una zona que daba cara a la contraescarpa y muralla occidentales de

78 Journaal, t. 3, p. 110.

79 Bonours, Le memorable siege, pp. 154-155.

80 Bonours, Le memorable siege, p. 182; Journaal, t. 3, p. 150.

81 Bonours, Le memorable siege, p. 122*.

82 Bonours, Le memorable siege, pp. 160, 171.

83 Histoire, f. 4v; Bonours, Le memorable siege, pp. 100*-101*, 248. 
la ciudad: valones en el dique de Catrice en la playa, españoles en las dunas frente a la ciudad vieja y Helmont, italianos frente a la contraescarpa entre los bastiones de Oeste y del Pólder, y los regimientos valones y borgoñones frente a las fortificaciones del enemigo en el pólder. Detrás de estas zonas se encontraba el regimiento alemán.

Parece que desde aquel momento los cabos estuvieron menos dispuestos a invertir tiempo y hombres en la construcción de obras que beneficiaran a todos, y mucho menos a cooperar para compartir éxitos. Ya en octubre de 1601, Frangipani comunicó a Aldobrandino que muchas iniciativas en Ostende fracasaban por la rivalidad que mantenían las naciones, la cual se combinaba en esto con el espíritu apocado y flemático que mostraba el archiduque a la hora de tomar decisiones ${ }^{84}$. En los informes y relatos coetáneos sobran los ejemplos de lo que el nuncio denunciaba. A continuación, aportamos uno de ellos.

El 25 septiembre de 1601, una tormenta acompañada de marea viva inundó el pólder entero a través de la brecha que los asediados habían hecho en el Dique Verde - ya el 22 y 23 de agosto - para evitar que los asediadores pudiesen utilizarlo y acercarse así a la ciudad ${ }^{85}$. Desde antes del sitio este dique tapaba la apertura entre las dunas y la mencionada ciudad. La inundación destrozó trincheras y plataformas, y causó daños enormes. Muchos soldados se ahogaron por no saber nadar, se destrozó el hospital militar, muebles y armas flotaban en el agua, y se perdieron provisiones, pólvora y hasta piezas de artillería. Ante la amenaza de las tormentas de invierno, la construcción de un dique que protegiese el campo contra el agua del mar se convirtió en la prioridad del archiduque. Éste encargó a Messía parar cualquier otra obra con el fin de dedicar todo el material y mano de obra a este nuevo cometido ${ }^{86}$.

Como se trataba de un trabajo que se debía realizar a plena vista de los cañones y mosqueteros de la ciudad, el archiduque prefirió emplear a los propios soldados. Sin embargo, desde un principio los maestres de campo españoles rehusaron desplegar sus efectivos en la construcción. Posiblemente no tenían problema en que sus soldados cavasen trincheras y erigiesen parapetos, ya que la protección de su propio campamento y la construcción de los acercamientos necesarios para atacar las posiciones del enemigo formaban parte de sus obligaciones como infantes, pero opinaban que la tarea de construir diques y erigir nuevos reductos y plataformas de artillería debía ser efectuada por obreros civiles (pionniers). Alberto finalmente decidió no obligar a nadie, pero ofreció un sueldo complementario a aquellos soldados que quisiesen trabajar en la construcción del dique. Los borgoñones, valones y alemanes no tuvieron problemas en aceptar la oferta, pero los cabos españoles y los italianos rehusaron aceptar que sus tropas hiciesen este tipo de trabajo por dinero, invocando su

84 Correspondance d'Ottavio Mirto Frangipani, t. 3, pp. 268-269.

85 Journaal, t. 3, pp. 136-137.

86 Bonours, Le memorable siege, p. 125*. 
reputación. Incluso trataron de impedir «avec seuerite» que los soldados que habían aceptado el trato ejecutasen el trabajo ${ }^{87}$.

El fracaso del asalto del 7 de enero de 1602 dificultó aún más las cosas. Aquel día perecieron centenares de hombres y se desvanecieron miles de escudos en un ataque general sin que los sitiadores progresasen ni un metro. En las semanas y meses siguientes empezó a faltar el dinero, el material y, como consecuencia de la falta de financiación, los efectivos para continuar las obras iniciadas. Por tanto, Messía y después Ribas se vieron obligados a dar prioridad a aquellas de las que mejores resultados se esperaban. Después del desastre del asalto general, se optó por interrumpir el abastecimiento de la ciudad tanto por el puerto viejo como por el nuevo. En el Cuartel de San Alberto se inició la construcción de una plataforma gigantesca — su altura definitiva sería de más de cuarenta metros - desde donde se podía disparar a cualquier parte de la ciudad asediada. En el Cuartel de Bredene, se optó por levantar un dique - llamado «de Bucquoy»— desde el fuerte de San Carlos hacia el río Geule, y prolongarlo en dirección a su desembocadura, para así hundir las lanchas que entraban en el nuevo puerto. Las otras obras, entre ellas la protección y comunicación de los reductos en el pólder mediante gaviones y fajinas, sólo se financiarían si había dinero disponible, aunque se decidió mantenerlas en buen estado ${ }^{88}$. Como consecuencia, en 1602 los asediadores avanzaron muy poco: en varios momentos ni siquiera hubo dinero para costear las obras de la plataforma y el dique, y con frecuencia tanto el cañoneo del enemigo como las mareas deshacían en un par de horas o días el trabajo de meses $^{89}$.

Es posible que la reforma del ejército, decretada por Alberto en marzo de 1602, fuera un intento de contrarrestar, en alguna medida, el problema de la rivalidad entre las naciones (Esteban Estríngana, 2012a, pp. 266-272). Con ella, el archiduque convirtió los regimientos valones en tercios y a sus coroneles en maestres de campo, procedimiento que unos meses después repetiría con los regimientos borgoñones. Desde ese instante, los tercios valones y borgoñones estaban en términos organizativos en pie de igualdad con españoles e italianos. Si fue un intento de neutralizar el antagonismo entre las unidades y sus cabos responsables, no acabó de dar los frutos deseados. En parte, porque los tercios españoles ya no solo vieron amenazados su estatus y las garantías de promoción correspondientes por los italianos, sino también por todos los demás. Por otro lado, los maestros de campo valones y borgoñones se sintieron desfavorecidos, ya que, desde el punto de vista retributivo, la reforma no les igualó del todo a españoles e italianos — el archiduque no había querido provocar a éstos más de lo necesario.

87 Bonours, Le memorable siege, pp. 125-129, 152-153.

88 Bonours, Le memorable siege, pp. 209-210, 222.

89 Bonours, Le memorable siege, pp. 221, 224, 232, 241, 246. 
En los meses posteriores la rivalidad entre los tercios se manifestó sobre todo en la pérdida de Grave, en el verano de 1602, aunque hay señales de que en Ostende esta también aumentó. En este periodo, Catrice insistió varias veces en un ataque sobre las fortificaciones del enemigo en el pólder y hasta envió a un espía adentro que luego le confirmó que estaban mal mantenidas y protegidas, pero no obtuvo el apoyo de los maestres de campo españoles para el asalto. De resultar exitoso, su plan implicaba que los reductos españoles de Valdés y San Agustín dejarían de tener una función ofensiva. En esta ocasión, también entró en conflicto abierto con ellos. De ahí que luego, según Bonours, le acusaran ante el archiduque de ser «temeraire, turbulente, mutin, \& mal effectionné a leur nation». En lugar de aprobar el plan de Catrice, Ribas dio permiso a los maestres de campo españoles para construir una media luna con tres dientes delante de la Puerta de Occidente de la ciudad, y al regimiento borgoñón de Claude de Rye, barón de Balançon, el hermano de Varambon que le había sucedido como maestre de campo de su tercio, de erigir un fuerte que se llamaría San Andrés ${ }^{90}$.

El dique y la plataforma tardaron más de un año en terminarse. La plataforma entró en acción el 23 de marzo de 1603, el mencionado dique se construyó en diferentes fases ${ }^{91}$. Una vez terminada la plataforma, y motivados por la llegada de nuevas tropas y material, los cabos solicitaron autorización para ejecutar otra facción ofensiva. Catrice volvió a proponer un ataque al pólder, pero los maestres de campo propusieron la construcción de unos acercamientos que salieran directamente de sus trincheras. Ribas presentó las propuestas al archiduque, esta vez apoyando la de Catrice, tras lo cual Alberto se decidió por el pólder ${ }^{92}$. Sin embargo, como Simon Antúnez y Álvaro Suárez no mostraron gran entusiasmo, «sachans que le principal honneur, qui s'attendoit de cette action, appartiendroit à Catriz», y dijeron «sans trop offenser, \& entierement dégouter les Maistres de Camp de ces nations [borgoñones y valones]», que no podían participar en tal empresa. Para hacerles cambiar de idea, Ribas les propuso asaltar la media luna que se situaba frente a la entrada del puerto nuevo. El 13 de abril de 1603 los tercios de Catrice, Balançon y Frésin asaltaron el pólder, echaron a los ingleses, y lo defendieron contra la ciudad. Los españoles, en cambio, no lograron tomar la media luna ${ }^{93}$.

Después de casi dos años de sitio, los asediadores habían ganado un punto estratégico desde donde asaltar la misma ciudad, y lo habían hecho los regimientos valones y borgoñón. Probablemente por esta razón la rivalidad entre las naciones impidió que se optase por forzar una brecha en la muralla desde el terreno recién

90 Bonours, Le memorable siege, pp. 248-250, 285, 291.

91 Bonours, Le memorable siege, pp. 241, 245, 252, 261, 269, 270, 299.

92 Bonours, Le memorable siege, pp. 304-307, 317, 319, 324.

93 Bonours, Le memorable siege, pp. 325-326, 331-339. 
conquistado. Las discusiones entre los maestres de campo sobre cómo proseguir el sitio - empezar los acercamientos desde el pólder conquistado o también construir acercamientos desde los sectores español e italiano - terminaron en que cada nación los iniciaría desde sus propias posiciones. Algunos maestres de campo incluso rehusaron la ayuda de otros cuando eran atacados por el enemigo, como sucedió el 14 de junio. Ese día, Balançon rechazó la ayuda de doscientos soldados españoles cuando los holandeses atacaron su fuerte en el pólder ${ }^{94}$. Posiblemente fue una reacción a los intentos previos de los cabos españoles de reservarse, a sus tercios, las acciones bélicas que ofrecían mayores perspectivas de éxito y, por tanto, de honor.

\section{De rivalidad a soberbia}

La rivalidad entre las naciones iba acompañada a veces de un fuerte sentimiento de superioridad por parte de españoles e italianos, y de manifestaciones de menosprecio hacia los otros regimientos. Esta actitud ocasionaba malestar entre los demás soldados y, en ocasiones, provocaba deserciones entre las demás tropas. Sus cabos, y en particular los «naturales», se irritaban frecuentemente por lo que ellos llamaban la «soberbia» de los españoles. Bonours relata que el sentimiento general entre los restantes efectivos era que los españoles les «tiennent inferieures» ${ }^{95}$. Estas muestras se manifestaban más claramente a nivel de la oficialidad: sólo hay que dar el ejemplo de Don Luis de Velasco, en 1602 promovido a capitán general de la caballería, quien anunció en octubre de 1603 que no tenía la intención de obedecer las órdenes de Ambrogio Spínola, el recién nombrado gobernador del ejército sitiador, por ser genovés y tener poca experiencia militar (González de León, 2009, p. 94). Según Spínola, Alberto y Frangipani, Velasco también saboteó el socorro de Sluis en agosto de 1604, conquistada por los holandeses un mes antes de la toma de Ostende, y cuya pérdida no sólo puso en peligro la posición del genovés, sin duda el propósito de Velasco. También causó gran descontento en la provincia de Flandes, que vio el dinero y el esfuerzo de tres años aniquilados por la pérdida de una ciudad desde donde la República podía de nuevo poner la provincia bajo contribución ${ }^{96}$.

El menosprecio también se manifestaba en la colaboración diaria de las naciones en el campo de batalla, a veces con consecuencias graves. Cuando, por ejemplo, Alberto ordenó reparar el dique que Catrice había construido frente a la ciudad vieja, los cabos españoles no sólo rehusaron desplegar a sus soldados en la obra, sino que además sugirieron que eran los valones, borgoñones y alemanes quienes debían hacer el trabajo por sorteo, si era necesario. Esto a su vez provocó la indignación de

94 Bonours, Le memorable siege, pp. 379-380, 392.

95 Bonours, Le memorable siege, p. 154.

96 Correspondance d'Ottavio Mirto Frangipani, t. 3, p. 486. 
los capitanes de éstos, algunos de los cuales renunciaron a su cargo argumentando que ellos también eran «gens de combat, \& Soldatz, non Manoeuures, ou Pionniers: Et qu'ilz ne se tenoint pas moins precieux que les Espagnolz, Italiens, \& Irlandois, qu'on exceptoit de cette couruee». Según Bonours, varios soldados abandonaron el campo o incluso desertaron al enemigo ${ }^{97}$.

Algo similar pasó en el verano de 1603, cuando, como resultado de un ataque con fuegos artificiales, el dique de Bucquoy ardió durante veinticinco días sufriendo severos daños. Un maestre de campo español, cuyo nombre tampoco nombra Bonours, sugirió a esta ocasión que para repararlo se trajese a los galeotes de Sluis — que servían en la flota de Federico Spínola - o, si esto era demasiado complicado, que se usase a los valones y alemanes, ahorrando de esta manera gran cantidad de dinero al rey. Sus oficiales se sintieron ofendidos por ser igualadas sus tropas a esclavos y divulgaron la noticia del incidente entre sus soldados, lo cual provocó «la haine de la pluspart des autres [naciones]» y la salida de cuatrocientos hombres del campo ${ }^{98}$. Por la misma, cuando en agosto del mismo año la guarnición asediada logró incendiar la plataforma mediante fuegos artificiales, Suárez rechazó el requerimiento de las otras naciones de colaborar en la extinción del fuego (una operación considerada de gran riesgo y, por tanto, honrosa, ya que el enemigo había puesto a dos mil mosqueteros en la contraescarpa para impedirlo), diciendo que «l'action n'étoit digne d'eux», lo que de nuevo originó la salida del campo de un buen número de soldados. Otros en cambio optaron por desertar a la ciudad, mientras que los franceses de las compañías libres rehusaron servir en las trincheras españolas hasta que fueron obligados a ello por Ribas y Antúnez ${ }^{99}$. Es probable que el incidente incitara a muchos a participar en el motín que dos mil soldados prepararon unas semanas más tarde, y cuyos instigadores fueron descubiertos a última hora ${ }^{100}$. Si este motín se hubiera producido, el sitio probablemente habría terminado en fracaso.

En una carta escrita el 25 de octubre de 1603, poco después del nombramiento de Ambrogio Spínola, Frangipani criticó acerbamente la organización del ejército de Flandes. Según el nuncio,

nell' esercito sono Soldati, ma non gente di comando; voluntà di combattere, ma dopo persa l'occasione; discordie, non unioni; diffidenza, non confidenza; licenza, non disciplina; dinaro, ma ritenuto non distribuito; sospetti, non fede. Et Consiglieri infiniti da guerra, senza nissun di loro chiamar' in Consiglio, ch 'al mio parecer' è la scaturigine di tutti disordini del male, posciache col riformarse questo capo solo se riformaria facilmente il resto, atteso che questi consiglieri neglitti non solamante

97 Bonours, Le memorable siege, p. 127*.

98 Bonours, Le memorable siege, pp. 416-417.

99 Bonours, Le memorable siege, pp. 405-406.

100 Bonours, Le memorable siege, pp. 419-421. 
s'allegrano d'i mali soccessi, et può dirse che col voto serveno al nemico, ma se ritirano di dimostrar' al principe l'errori et l'inconvenienti anteveduti ${ }^{101}$.

Sus palabras esbozan poco menos que un panorama degradante del aparato militar más poderoso de su tiempo, que en más de dos años apenas había logrado progreso en un sitio que se había convertido en la prueba por excelencia de la reputación tanto del archiduque como de Felipe III y la «nación espanola».

\section{Los cambios de Spínola}

Las cosas cambiaron con la llegada de Ambrogio Spínola en octubre de 1603. Cuando Alberto se enteró, probablemente en mayo de aquel año, de que Madrid estaba concretando el envío de un lugarteniente para que le asistiese en el mando del ejército, y se dio cuenta de que la conquista del pólder aún no había permitido iniciar el avance definitivo, negoció un acuerdo con el genovés para que él se encargase del sitio y adelantase todos los gastos hasta la toma de la ciudad. Los dos firmaron el contrato a finales de septiembre, y Felipe III lo aprobó a inicios de noviembre (Esteban Estríngana, 2021b).

Spínola había preparado bien su decisión. Primero, durante el verano el marqués había hecho reconocer el terreno tanto por su sargento mayor Pompeo Giustiniano como por el coronel veneciano Giacomo Franceschi, sin que el uno supiera del otro $^{102}$. Sólo cuando ambos confirmaron por separado que era posible conquistar la ciudad, Spínola aceptó el trato. En segundo lugar, Spínola había exigido de Alberto la «entiere surintendance, \& regiment du camp». Por tanto, el archiduque escribió a Ribas para que entregase el mando y se presentase en la corte, y a los otros cabos para obligarles a obedecer las órdenes del marqués y «luy deferer, en tout ce qui re-

101 Correspondance d'Ottavio Mirto Frangipani, t. 3, p. 438. La opinión negativa que Frangipani tenía del ejército español también era el resultado de su experiencia personal con los amotinados de Hoogstraten. Este motín surgió durante el socorro de Grave en el verano de 1602. Después, los amotinados se instalaron en Hoogstraten. En el otoño, Frangipani se ofreció como negociador entre Alberto y los amotinados y viajó dos veces (en vano) hacia su campo. En el verano de 1603, Alberto decidió asediarlos, pero los amotinados hicieron un acuerdo con Mauricio de Nassau, quien inmediatamente les envió un ejército. El sitio fracasó y la retaguardia del ejército de Flandes incluso fue atacada al retirarse. En sus cartas sobre este asunto, Frangipani mostró poca comprensión hacia los amotinados, no sólo porque su comportamiento puso en peligro la seguridad de Brabante, sino también porque comprometió el buen desenlace de las operaciones en Ostende. El motín duró hasta 1606 y fue el más largo de toda la Rebelión de Flandes (véase Danckaert, 2019). Como la rivalidad entre los cabos del ejército había desempeñado un papel importante en el socorro de Grave, se entiende mejor esta imagen de discordia que Frangipani esbozó en su carta (véase también Esteban Estríngana, 2012a).

102 Pompeo Giustiniano, Delle gverre di Fiandra libri VI, Amberes, Joachim Trognesius, 1609, p. 68. Para un análisis reciente sobre Spínola y el sitio de Ostende (véase Duerloo, 2012, pp. 123-142; Retortillo Atienza, 2017, pp. 97-174; Benavides, 2018, pp. 27-53). 
gardoit le seruice de sa Majesté, deuoir, respect, \& obeissance» ${ }^{103}$. A la luz de todos los conflictos que en los años anteriores se habían generado, esta última frase era sin duda más que una fórmula estereotipada. Desde aquel momento, Alberto se inhibió de la empresa y ya no apareció por Ostende ni Nieuwpoort hasta después de su caída (Thomas, 2004b, pp. 97-98).

Spínola llegó al campo el 8 de octubre y se instaló en el fuerte de San Alberto. Allí le esperaban los cabos de los tercios para saludarle y recibir las primeras órdenes. Spínola marcó inmediatamente el tono con un discurso en el que puso mucho énfasis en la jerarquía y la obediencia, comparando el ejército con una orden religiosa que tenía una sola regla y diferentes grados y dignidades, pero cuyos miembros obedecían a un solo director. Les dijo que odiaba la arrogancia y la presunción. Pero también que se daba cuenta de que había otros mucho más hábiles que él para el puesto; pese a ello, que el capitán general había optado por él y él, como buen soldado, había aceptado. Buscó su colaboración refiriéndose a ellos como «braues, \& dignes Chefz de guerre», de los que esperaba «tout conseil, \& confort» y plena cooperación, advirtiéndoles que era él quien financiaba las operaciones. Finalmente les recordó que el orgullo y la ambición personal no pueden estorbar el «bien public» ${ }^{104}$. Por su discurso, es obvio que se había informado sobre la dinámica que mantenían los oficiales mayores en el campo.

Inspeccionó luego los diferentes sectores del campo, algo que continuó haciendo durante el resto del asedio y que tanto Alberto como los cabos habían dejado de hacer. De hecho, a partir de agosto de 1601 se seguía un sistema de guardia en el que los maestres de campo se turnaban semanalmente en las trincheras, salvo cuando una acción ofensiva requería su presencia. Spínola, en cambio, aparecía de día y de noche, muchas veces sin anuncio previo. No solo visitaba las zonas seguras detrás del frente, sino también las más peligrosas, como los acercamientos. Bonours cuenta que en esas ocasiones los que le acompañaban varias veces temieron que muriera por una bala del enemigo ${ }^{105}$. Bentivoglio subrayó esta cualidad suya: «y quando se halla en el exercito, no muestra menos ser el primero de todos en el padecer descomodidades, que en exercitar el imperio sobre los demas» ${ }^{106}$. Además, el marqués obligó a los cabos a estar en persona en sus sectores para supervisar las obras, lo cual forzaba a los otros oficiales a atender también sus trincheras, algo que, según Bonours, antes no siempre se hacía ${ }^{107}$. Fue en estos meses que Balançon resultó herido en combate y que Catrice murió de un balazo que recibió en el hombro ${ }^{108}$.

103 Bonours, Le memorable siege, p. 434.

104 Bonours, Le memorable siege, pp. 434-437.

105 Bonours, Le memorable siege, pp. 449-450, 487-488, 507, 519.

106 Puteanus, Relaciones, p. 161.

107 Bonours, Le memorable siege, p. 113*.

108 Bonours, Le memorable siege, pp. 462, 500. 
Las visitas a las trincheras le servían para mantener una buena relación con los soldados comunes. Ya había ganado su simpatía pagando sus sueldos, enteros y a tiempo, y restaurando el orden en el campo. Además, durante esas visitas daba recompensas en forma de dinero y promociones por el trabajo realizado en zonas de peligro y, particularmente, por el efectuado en los acercamientos. Aumentó asimismo el personal del hospital y lo proveyó de más medios. Finalmente, aseguró el abastecimiento, de forma que, según Bonours, la abundancia de productos disponibles en las tiendas del campo era tal, «que les plus abondantes villes d'Europe eussent icy trouué qu'enuier» ${ }^{109}$. Con todas estas medidas se ganó el afecto de sus tropas, algo que Alberto no había podido lograr ${ }^{110}$.

Su solución al problema de la rivalidad entre los cabos es más difícil de analizar a partir de las fuentes disponibles. Da la impresión de que logró sacar a las personas más conflictivas del sitio, como Velasco y posiblemente también Dávalos. No se conoce con detalle el vaivén de los cabos y sus tercios. En los tres años del asedio, algunos fueron retirados de forma transitoria y otros de modo permanente. Hubo cabos que salieron y volvieron, como Catrice, seguramente una persona conflictiva con los españoles, y los hubo que, una vez fuera, ya no volvieron al asedio, como van den Bergh. De los «naturales», Varambom - insatisfecho con los resultados de la reforma de 1602 - renunció a su tercio y fue sucedido por su hermano Balançon, pero no da la impresión de que fuese una persona difícil. Bucquoy y Gruson estuvieron casi permanentemente, pero no fue en su parte de campo donde se produjeron los conflictos. Frésin también estuvo casi todo el tiempo. De los italianos, Spínola pudo tener plena confianza en su propio tercio, posteriormente dirigido por Guistiniano. Los de Lelo Brancaccio y el conde de Trivulcio, y las compañías de Dentici apenas se mencionan en las fuentes, lo cual posiblemente sea una señal de poca conflictividad. De los españoles, Monroy y Villar fallecieron en una fase temprana del asedio, mientras que Ribas se retiró a su llegada; Messía ya había abandonado el sitio antes. Antúnez iba y volvía. Por otro lado, Suárez se quedó casi todo el tiempo y fue sin duda uno de los españoles que más se opusieron a los «naturales». Pero al inicio de la primavera de 1604, Spínola trajo otros dos tercios españoles que hasta entonces no habían servido en el asedio: el de Juan de Meneses y el de Iñigo de Borja. ¿Podría ser que, como recién llegados, éstos no tuvieran inconveniente en aceptar las condiciones de Spínola, de forma que los cabos conflictivos quedaron en minoría?

Lo que sus medidas no resolvieron del todo fue la rivalidad entre las naciones. Pero aquí también tenía una ventaja en comparación con sus antecesores: disponía de capital necesario para financiar cualquier iniciativa. Bonours subraya la abundancia

109 Bonours, Le memorable siege, pp. 473-474.

110 Archivo General de Simancas, Estado, n ${ }^{\circ}$ 622: informe del conde de Solre sobre los motines en Flandes, Gante 1603. 
de material y municiones. Spínola se permitió el lujo de no tener que escoger entre las propuestas de los cabos. Aunque su táctica inicial fue impedir la llegada de provisiones alargando el dique de Bucquoy hacia la desembocadura del río Geule y empezar los acercamientos desde los fuertes conquistados en el pólder, también dio permiso a los tercios españoles e italianos para iniciar acercamientos desde sus posiciones ${ }^{111}$. De esta manera reconoció la importancia para éstos de tener sus propias operaciones para asaltar la ciudad.

A partir de ese momento, Spínola evitó la envidia entre las naciones manejando los progresos de tal forma que nadie se sintiese en desventaja. Cuando italianos, valones y borgoñones - estos dos unieron fuerzas en la fase final del asedio- llegaron al foso de la contraescarpa y solicitaron autorización para penetrarlo, los detuvo dando la oportunidad a los españoles de acercarse más al canal delante de Porcespic. Una vez llegados allí, éstos se dieron cuenta de que era más profundo de lo esperado, y de que necesitaban una presa usando los renombrados salchichones (Thomas, 2018); enseguida Spínola dio orden a los otros de no avanzar y de trabajar en la protección de sus flancos. Mientras los españoles estaban terminando la construcción de su presa, los demás obtuvieron el permiso de cruzar el foso y tomar la contraescarpa. Luego empezaron a trabajar en la travesía del foso de la ciudad y se instalaron en el pie de los bastiones del Oeste (italianos) y del Pólder (valones y borgoñones). Ya situados en ellos, los italianos y valones / borgoñones contemporizaron esfuerzos hasta que Antúnez y Suárez estuvieron listos para atacar Porespic, y luego les asistieron efectuando un ataque falso a sus respectivos bastiones. Tomado Porcespic, los españoles lo fortificaron contra la ciudad y se dirigieron a Helmont, al mismo tiempo que los otros atacaban sus bastiones, ahora para tomarlos. Los borgoñones / valones entraron primero en la ciudad, los italianos fueron los siguientes. Tras fortificar sus posiciones, volvieron a esperar a que los españoles tomasen Helmont. Allí se descubrió que el enemigo había hecho una segunda cadena de bastiones detrás de la primera. Los atacantes instalaron entonces baterías en los bastiones conquistados, los españoles con cierto retraso, y el 25 de julio 1604, día de Santiago, abrieron fuego conjunto contra la segunda muralla, forzando al enemigo a retirarse. Una vez bien instalados, Spínola salió con parte de sus tropas para socorrer a Sluis ${ }^{112}$.

Al haber mejorado la coordinación entre los tercios españoles, italianos, valones y borgoñones, Spínola dio solución al último conflicto que se incubaba en el campo. Durante esos meses, el regimiento alemán del coronel Lutzelburg había servido de reserva y, por esta razón, Spínola no lo había querido destacar. Los oficiales alemanes, viendo que las otras naciones estaban participando en el honor de conquistar la ciudad, mientras que de ellos nadie se acordaría, pidieron a Spínola les permitiera

111 Bonours, Le memorable siege, p. 446.

112 Bonours, Le memorable siege, pp. 524, 525, 533, 546, 568, 570, 572. 
combatir con los otros. El marqués, en vez de emplearlos como tropas de apoyo, les asignó Zandhill, el bastión mejor fortificado y, en consecuencia, el más difícil de tomar. Haciendo «grande demonstration de contentement» iniciaron el ataque y en los días siguientes no sólo tomaron Zandhill, sino también Schottenburg y la ciudad vieja, «faisant admirer leur promtitude \& se mettans aupres de tous en excelente estime». Mientras tanto, las otras naciones habían conquistado la segunda muralla y se topaban con una tercera, recién construida. Los defensores, habiéndose retirado a lo que llamaron la «Pequeña» o «Nueva Troya», intentaron una última salida contra las posiciones alemanas, pero al fracasar, aceptaron a negociar la rendición en la mañana del 20 de septiembre de $1604^{113}$. En menos de siete meses, si no se cuentan los de inactividad del invierno de 1603, y a pesar del retraso causado por el socorro de Sluis, Spínola logró lo que Alberto no pudo hacer en más de dos años.

\section{Conclusión}

Durante el sitio de Ostende, el ejército de Flandes aparece más de una vez como un cuerpo mal organizado, mal gobernado, con poca cohesión entre sus componentes, en particular cuando éstos pertenecían a diferentes naciones, y dependiendo de un capitán general irresoluto y a veces con poca autoridad. Obviamente, no faltaron razones para que el ejército rindiera menos: circunstancias geográficas y condiciones atmosféricas difíciles, un enemigo atrincherado en una ciudad fuertemente fortificada y con líneas de abastecimiento difícilmente interrumpibles, dificultades de financiación, acciones bélicas en otras partes del país a las que se debía responder, etc. Pero el mismo funcionamiento — en sentido amplio — del ejército también contribuyó al fracaso. Puede que Bonours tuviese cierta antipatía por los maestres de campo españoles y que, en su relato, pusiese más énfasis en la responsabilidad que podían tener en los conflictos, minimizando el papel de los demás. No obstante, lo importante es que la rivalidad entre cabos y naciones - quienquiera que fuese el instigador de la misma - unas veces paralizaba las operaciones y otras las saboteaba, y tenía globalmente un efecto disruptivo mucho mayor que la rivalidad entre cabos de la misma nación, si es que la hubo - ya que ni Bonours ni las fuentes holandesas la mencionan. Por falta de liderazgo firme, el poder en Ostende estuvo en manos de cabos que, bien por no ponerse de acuerdo entre sí, bien por rencor personal o bien por menosprecio de las unidades de las otras naciones, hipotecaron el alcance de una empresa que tanta importancia tenía para la población flamenca, para la autoridad del archiduque y para el destino de la Casa de Habsburgo en los Países Bajos, aunque no parece que ninguno fuese consciente de ello en su momento.

113 Bonours, Le memorable siege, pp. 579-587, 592, cita en la p. 585. 
En este sentido, el caso de Ostende contradice en cierta medida el análisis del declive que se ha hecho del ejército de Flandes. Para explicarlo, autores como Fernando González de León invocan la pérdida de la posición eminente de los tercios españoles dentro del ejército, el cambio en la política de reclutamiento y en la promoción de los oficiales mayores, y el clientelismo del rey (o en nuestro caso, del archiduque), que favoreció la entrada de nobles sin vocación militar en la oficialidad, idealizando la época del duque de Alba, cuando el ejército era una organización casi exclusivamente española. Pero en Ostende el ejército logró tomar la ciudad bajo el mando, no de un oficial español experimentado, sino de un noble genovés - aunque algunos cabos españoles prefirieron referirse a él como «mercader»- recién nombrado y sin mucha preparación previa, mientras que el papel principal en los momentos más críticos del desenlace lo desempeñaron los tercios de «naturales» y los regimientos alemanes y no las unidades españolas. Comparando los meses en Ostende antes y después de la llegada de Ambrogio Spínola, uno no puede dejar de atribuir su éxito repentino, aparte de a sus recursos económicos, a sus capacidades como people manager. Spínola entendió mejor que Ribas, Messía o incluso que Alberto las sensibilidades de cada una de las naciones y sus cabos y, si bien no logró eliminar la rivalidad entre ellas, supo manejarla mejor que sus predecesores.

Un aspecto al que no se le ha dado mucha importancia hasta ahora. El análisis que la historiografía reciente ha hecho de la actuación de Alberto como capitán general y de los cambios introducidos por Spínola desde Ostende insiste en dos puntos: la poca capacidad de Alberto como jefe militar — en el sentido en que no supo tomar las decisiones tácticas y estratégicas adecuadas - y los abundantes recursos financieros de Spínola. González de León (2009, p. 12) sostiene que Alberto «lacked Parma’s military genius and resources», mientras que Spínola sobresalía por su «able leadership», sin especificar en qué consistía esta habilidad. Retortillo Atienza (2017, pp. 140-143) y Benavides (2018, pp. 32-34 y pp. 43-50) subrayan el aspecto financiero y el plan de ataque de Spínola. Duerloo (2012, p. 138) insiste en la imagen negativa que Madrid tenía de Alberto, dejando entre líneas si esa imagen se ajustaba a la realidad o no. En cuanto al éxito de Spínola, lo atribuye, además de a sus capacidades financieras, al hecho de que supo acabar con las rivalidades que se manifestaban en el seno del ejército, dando a cada nación su propio «set of tasks». Pero, como demuestra este artículo, la rivalidad no desapareció, mientras que el argumento financiero sólo explica en parte el éxito de Spínola. Al iniciar el sitio en el verano de 1601, Alberto también dispuso de una cantidad considerable de dinero y material, y no pudo hacer los avances que Spínola sí hizo después.

El caso de Ostende demuestra una vez más que el ejército de Flandes era una máquina de guerra compleja — con su propia dinámica interna que más de una vez hipotecó y a veces saboteó el resultado de una campaña militar — más allá de la falta 
circunstancial de una financiación adecuada. Pero también demuestra que en manos de un capitán general hábil que sabía manejar las divisiones internas, esta máquina podía obtener resultados excelentes. Al respecto, su nombramiento como maestre de campo general - en lugar de Agustín Messía, preferido por el rey - fue la decisión más oportuna que Alberto pudo imponer a Felipe III. El archiduque sin duda se había dado cuenta de que Spínola le había salvado el pellejo — una derrota ante Ostende, combinada con un motín general de las tropas, el descontento de los estados de Flandes, un ataque holandés en Brabante en ayuda de los amotinados de Hoogstraten y el disgusto de Madrid hubieran conducido indudablemente a su destitución como capitán general e incluso a su traslado, junto con la infanta, a otro territorio de la Monarquía Hispánica - y contaba con que continuara haciéndolo en el futuro. Es cierto que, sin Alberto no hubiera habido Spínola, pero también que, sin Spínola, no hubiera habido Alberto.

Finalmente, la victoria ante Ostende pudo haber suavizado las rivalidades en el ejército al menos momentáneamente. Sin embargo, con el tiempo parece que estimuló más el desarrollo de las facciones en la corte de Bruselas. El fracaso de Sluis influyó en la relación entre Velasco y Spínola, mientras que el nombramiento de éste como maestre de campo general provocó el malestar de Messía, el candidato de Madrid. Ambos se juntaron en una facción anti-Spínola, y pronto recibieron el apoyo de Juan de Ribas, al que Spínola sustituyó en Ostende, e Iñigo de Borja, cuñado de Velasco (Thomas, 2014, pp. 212-221), entre otros. En los años siguientes, se opusieron a una tregua con las Provincias Unidas, luego intentaron torpedearla con un asalto a Sluis y, finalmente, hicieron todo lo posible para limitar el poder de Spínola en la corte de Bruselas. En este sentido, no sólo sería interesante estudiar con más detalle el papel de las rivalidades internas en las campañas coetáneas, sino también las relaciones personales entre los cabos del ejército, los nobles de la corte en Bruselas y Madrid, y los miembros de la administración real y archiducal, para así entender mejor tanto la dinámica interna del ejército como su posible influencia en el gobierno del país.

\section{AGRADECIMIENTOS}

Este artículo es el resultado de mi colaboración en el Proyecto I+D Excelencia Conformar la Monarquía Hispánica: cultura política y prácticas dinásticas en los siglos XVI y XVII (HAR2016-76241-P), financiado por el MINEICO-FEDERA. Agradezco a Alicia Esteban Estríngana y a los demás evaluadores la revisión del texto y sus reflexiones y comentarios sobre el contenido. La edición de este trabajo ha sido posible gracias a la ayuda del Programa de Grupos de Potencial Crecemento concedida por la Consellería de Cultura, Educación e Universidade da Xunta de Galicia al GI-1921 de la USC (Referencia: GPC, ED 431B 2021/06). 


\section{Bibliografía}

Benavides, José Ignacio (2018), Spinola, capitán general de los tercios. De Ostende a Casal, Madrid, La Esfera de los Libros.

CARTer, Charles (1964), «Belgian 'Autonomy' under the Archdukes, 15981621», The Journal of Modern History, 36 (3), pp. 245-259. <https://doi. org/10.1086/239425>.

DANCKAERT, Laura (2019), «'Groene geuzen’. Een casestudy naar de Unie van Hoogstraten (1602-1605) », Jaarboek Erfgoed Hoogstraten, 8, pp. 5-115.

De Vos, Luc (1995), «Het Beleg van Oostende, 1601-1604», en De Vos, Luc (coord.), Veldslagen in de Lage Landen, Leuven, Davidsfonds, pp. 79-87.

Duerloo, Luc (2012), Dynasty and Piety: Archduke Albert (1598-1621) and Habsburg Political Culture in an Age of Religious Wars, Farnham, Ashgate.

Elías de Tejada y Sínola, Francisco (1975), El Franco-Condado hispánico, Sevilla, Ediciones Turra.

Esteban Estríngana, Alicia (2012a), «Cabos de Guerra: satisfacción de la oficialidad y eficacia bélica en el Ejército de Flandes, entre los siglos XVI y XVII», en Pardo Molero, Juan Francisco y Lomas Cortés, Manuel (coords.), Oficiales reales. Los ministros de la Monarquía Católica (siglos XVI-XVII), Valencia, Universidad de Valencia, pp. 273-282. <https://doi. org/10.1163/9789004446267_008>.

Esteban Estríngana, Alicia (2012b), «Paréntesis bélico y reformación militar en el período de los Archiduques. Fundamentos de la acometida reformista de 1609», en García García, Bernardo José, Herrero Sánchez, Manuel y Hugón, A. (coords.), El Arte de la Prudencia. La Tregua de los Doce Años en la Europa de los Pacificadores, Madrid, FCA, pp. 425-485.

Esteban Estríngana, Alicia (2021a), «The 'Perfect Principality' of the Archdukes Albert and Isabella: Project and Reality of a 'Separate Government' of the Spanish Crown, 1529-1621», en De Bom, Erik, Lesaffer, Randall y Thomas, Werner (coords.), Early Modern Sovereignties: Theory and Practice of a Burgeoning Concept in the Netherlands, Leiden, Brill, pp. 167-217.

Esteban Estríngana, Alicia (2021b), «A Joab for King David. Ambrogio Spinola, General of Archduke Albert, and the Davidic Imaginary in Times of Philip III (1598-1605)», en Mostaccio, Silvia, García García, Bernardo José y Lo Basso, Lucca (coords.), Ambrogio Spinola between Genoa, Flanders and Spain, Lovaina, University Press Leuven [en prensa]. 
GonzÁlez de León, Fernando (2009), The Road to Rocroi: Class, Culture and Command in the Spanish Army of Flanders, 1567-1659, Leiden \& Boston, Brill. $<$ https://doi.org/10.1163/ej.9789004170827.i-408>.

Helbig, Henri (1868), «Bonours, Christophe de», Biographie nationale, t. 2, pp. 687688.

Henrard, Paul (1890), Histoire du siège d'Ostende (1601-1604), Bruselas, C. Muquardt.

LeFÈVRE, Joseph (1923), «Les ambassadeurs d'Espagne à Bruxelles sous le règne de l'archiduc Albert (1598-1621)», Revue belge de philologie et d'histoire, 2, pp. 61-80. <https://doi.org/10.3406/rbph.1923.6213>.

LeFĖVRe, Joseph (1924), «Le ministère espagnol de l'archiduc Albert, 1598-1621», Bulletin de l'Académie royale d'Archéologie de Belgique, 6 (2), pp. 202-224.

Lombaerde, Piet (2004a), «Oostende afgesneden, belegerd, opgegeven en ingenomen: 1599-1604», en De Vries, Dirk (coord.), Oostende verloren Sluis gewonnen, 1604. Een kroniek in kaarten, Leiden, Universiteitsbibliotheek, pp. 47-69.

Lombaerde, Piet (2004b), «De stad Oostende en de nieuwe gebastioneerde versterkingswijzen in de Nederlanden», en Thomas, Werner (coord.), De val van het Nieuwe Troje, Lovaina, Davidsfonds, pp. 47-57.

Maltby, William S. (2011), Auge y caída del imperio español, Madrid, Marcial Pons, [traducción de Jesús Cuéllar Menezo].

PARKer, Geoffrey (1972), The Army of Flanders and the Spanish Road, 1567-1659, Cambridge, Cambridge University Press.

Piceu, Tim (2008), Over vrybuters en quaetdoenders. Terreur op het Vlaamse platteland (eind 16de eeuw), Lovaina, Davidsfonds.

Raeymaekers, Dries (2013), One Foot in the Palace: The Habsburg Court of Brussels and the Politics of Access in the Reign of Albert and Isabella, 1598-1621, Lovaina, Leuven University Press. <https://doi.org/10.2307/j.ctt9qdwz4>..

Retortillo Atienza, Asunción (2017), Ambrosio Spínola, de Génova a Ostende (1569-1604), Madrid, Ministerio de Defensa.

Salazar y Acha, Jaime de (s.f.), «Silva y Mendoza, Rodrigo de», en Real Academia de la Historia, Diccionario Biográfico electrónico (en red, <http://dbe.rah.es/ biografias/13880/rodrigo-silva-y-mendoza>).

Thomas, Werner (1999), «La corte de Bruselas y la restauración de la casa de Habsburgo en Flandes, 1598-1633», en VV. AA., El Arte en la Corte de los Archiduques Alberto de Austria e Isabel Clara Eugenia (1598-1633). Un Reino Imaginado, Madrid, Sociedad Estatal, pp. 46-63. 
Thomas, Werner (2004a), «De val van het Nieuwe Troje», en Thomas, Werner (coord.), De val van het Nieuwe Troje, Lovaina, Davidsfonds, pp. 7-19.

Thomas, Werner (2004b), «Het beleg van Oostende», en Thomas, Werner (coord.), De val van het Nieuwe Troje, Lovaina, Davidsfonds, pp. 81-99.

Thomas, Werner (2011), «Jerónimo Gracián de la Madre de Dios, la corte de Bruselas y la política religiosa en los Países Bajos meridionales, 1609-1614», en Vermeir, René, Ebben, Maurits y Fagel, Raymond (coords.), Agentes e identidades en movimiento. España y los Países Bajos, siglos XVI-XVIII, Madrid, Sílex, pp. 289-312.

Thomas, Werner (2014), «The 'Spanish Faction' at the Court of the Archdukes Albert and Isabella», en Vermeir, René, Raeymaekers, Dries y Hortal Muñoz, José Eloy (coords.), A Constellation of Courts: The Courts and Households of Habsburg Europe, 1555-1655, Lovaina, University Press Leuven, pp. 167221. <https://doi.org/10.2307/j.ctt14jxsxk.9>.

Thomas, Werner (2018), «Los ingenios del sitio de Ostende», Desperta Ferro, 36, pp. $18-22$.

Thomas, Werner (2020), «How a defeat became a victory: the siege of Ostend in contemporary Dutch war coverage and post-war chronicles (1601-15)», en Fagel, Raymond, Álvarez Francés, Leonor y Santiago Belmonte, Beatriz (coords.), Early modern war narratives and the Revolt in the Low Countries, Manchester, Manchester University Press, pp. 126-146.

Vlietinck, Edward (1897), Het oude Oostende en zijne driejarige belegering, Oostende, Jos Vlietinck. 